\title{
¿Severe Convective Storms across Europe and the United States. Part II: ERA5 Environments Associated with Lightning, Large Hail, Severe Wind, and Tornadoes $\mathscr{O}$
}

\author{
Mateusz TaszareK, ${ }^{\mathrm{a}, \mathrm{b}}$ John T. Allen, ${ }^{\mathrm{c}}$ Tomáš PúčIK, ${ }^{\mathrm{d}}$ Kimberly A. Hoogewind, ${ }^{\mathrm{e}, \mathrm{b}}$ \\ AND HAROLD E. BROOKs ${ }^{\mathrm{b}, \mathrm{f}}$

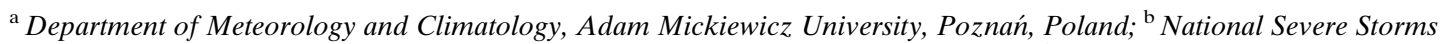 \\ Laboratory, Norman, Oklahoma; ${ }^{\mathrm{c}}$ Central Michigan University, Mount Pleasant, Michigan; ${ }^{\mathrm{d}}$ European Severe Storms Laboratory, \\ Wessling, Germany; ${ }^{\mathrm{f}}$ Cooperative Institute for Mesoscale Meteorological Studies, University of Oklahoma, Norman, Oklahoma; \\ ${ }^{\mathrm{e}}$ School of Meteorology, University of Oklahoma, Norman, Oklahoma
}

(Manuscript received 14 May 2020, in final form 5 August 2020)

\begin{abstract}
In this study we investigate convective environments and their corresponding climatological features over Europe and the United States. For this purpose, National Lightning Detection Network (NLDN) and Arrival Time Difference long-range lightning detection network (ATDnet) data, ERA5 hybrid-sigma levels, and severe weather reports from the European Severe Weather Database (ESWD) and Storm Prediction Center (SPC) Storm Data were combined on a common grid of $0.25^{\circ}$ and 1-h steps over the period 1979-2018. The severity of convective hazards increases with increasing instability and wind shear (WMAXSHEAR), but climatological aspects of these features differ over both domains. Environments over the United States are characterized by higher moisture, CAPE, CIN, wind shear, and midtropospheric lapse rates. Conversely, 0-3-km CAPE and low-level lapse rates are higher over Europe. From the climatological perspective severe thunderstorm environments (hours) are around 3-4 times more frequent over the United States with peaks across the Great Plains, Midwest, and Southeast. Over Europe severe environments are the most common over the south with local maxima in northern Italy. Despite having lower CAPE (tail distribution of $3000-4000 \mathrm{~J} \mathrm{~kg}^{-1}$ compared to $6000-8000 \mathrm{~J} \mathrm{~kg}^{-1}$ over the United States), thunderstorms over Europe have a higher probability for convective initiation given a favorable environment. Conversely, the lowest probability for initiation is observed over the Great Plains, but, once a thunderstorm develops, the probability that it will become severe is much higher compared to Europe. Prime conditions for severe thunderstorms over the United States are between April and June, typically from 1200 to 2200 central standard time (CST), while across Europe favorable environments are observed from June to August, usually between 1400 and 2100 UTC.
\end{abstract}

KEYWORDS: CAPE; Climatology; Convective storms; Reanalysis data; Diurnal effects; Seasonal cycle

\section{Introduction}

Observational records from lightning detection networks or severe weather reports produce straightforward but imperfect climatologies of severe convective storms, as presented in the first part of the study (Taszarek et al. 2020a, hereafter Part I). These data feature many spatial and temporal biases, and for some regions offer limited record length. In many parts of the world, severe weather reports are not even collected, which creates difficulties in constructing reliable climatologies. Due to these limitations, a typical practice has been to consider environmental proxies favorable to the development of severe thunderstorms and construct their climatologies (Johns and Doswell 1992; Griffiths et al. 1993; Doswell et al. 1996; Brooks et al. 2003).

Studies concerning environments collocated with specific hazards (tornado, large hail, severe wind, heavy rain) allow for better

\footnotetext{
๑ Denotes content that is immediately available upon publication as open access.
}

O) Supplemental information related to this paper is available at the Journals Online website: https://doi.org/10.1175/JCLI-D-200346.s1.

Corresponding author: Mateusz Taszarek, mateusz.taszarek@ amu.edu.pl; mateusz.taszarek@noaa.gov identification of atmospheric patterns favoring their occurrence, and hence improve anticipation by forecasters (Brooks et al. 2011; Hitchens and Brooks 2014). These studies are often based on data from upper-air measurements (Rasmussen and Blanchard 1998; Brooks 2009; Mohr and Kunz 2013; Púčik et al. 2015; Taszarek et al. 2017; Rodríguez and Bech 2018; Molina et al. 2020). However, sounding stations necessitate spatiotemporal proximity assumptions to severe weather events, which often exceeds $100 \mathrm{~km}$ and $4 \mathrm{~h}$ (Potvin et al. 2010). This can be problematic for parameters that are strongly sensitive to spatial or vertical variations in atmospheric profile, such as convective available potential energy (CAPE) or storm-relative helicity (Markowski et al. 1998). The use of reanalyses alleviates the challenges of temporal and spatial proximity of a sounding, but relies on a fixed model state and assimilated data representing conditions that are close to the true atmospheric state. Biases in thermodynamic and boundary layer parameters, such as CAPE or 0-1-km shear, have been noted by Allen and Karoly (2014), Gensini et al. (2014), Taszarek et al. (2018, 2019), King and Kennedy (2019), and Li et al. (2020) when comparing reanalyses to observed soundings.

Nowadays, the majority of studies use model data such as Rapid Update Cycle or reanalysis (Thompson et al. 2003;

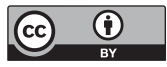

This article is licensed under a Creative Commons Attribution 4.0 license (http://creativecommons.org/ licenses/by/4.0/). 
TABLE 1. Datasets used in the study.

\begin{tabular}{lllll}
\hline \hline \multicolumn{1}{c}{ Category } & \multicolumn{1}{c}{ Database } & \multicolumn{1}{c}{ Sample size } & \multicolumn{1}{c}{ Resolution } & Coverage \\
\hline Lightning & United States-NLDN $^{\mathrm{a}}$ & 868335173 flashes & $0.25^{\circ} / 1 \mathrm{~h}$ & $1989-2018$ \\
& Europe-ATDnet $^{\mathrm{b}}$ & 180508624 flashes & $0.25^{\circ} / \mathrm{h}$ & $2006-2018$ \\
Severe weather reports & United States-SPC $^{\mathrm{c}}$ & 761956 reports & $0.25^{\circ} / 1 \mathrm{~h}$ & $1979-2018$ \\
& Europe-ESWD $^{\mathrm{d}}$ & 56733 reports & $0.25^{\circ} / 1 \mathrm{~h}$ & $1979-2018$ \\
Convective environments & ERA5 $^{\mathrm{e}}$ & 350640 time steps & $0.25^{\circ} / 1 \mathrm{~h} / 137$ model levels & $1979-2018$ \\
& & 72712 grid points & & \\
\hline
\end{tabular}

${ }^{a}$ National Lightning Detection Network (Koehler 2020).

${ }^{\mathrm{b}}$ The Arrival Time Difference Lightning Detection Network (Enno et al. 2020).

${ }^{\mathrm{c}}$ Storm Prediction Center Severe Weather Database (Schaefer and Edwards 1999).

${ }^{\mathrm{d}}$ European Severe Weather Database (Dotzek et al. 2009).

${ }^{\mathrm{e}}$ Fifth generation of ECMWF atmospheric reanalyses (Hersbach et al. 2020).

Kuchera and Parker 2006; Grams et al. 2012; Johnson and Sugden 2014; Tippett et al. 2015; Anderson-Frey et al. 2018). Brooks et al. (2003) conducted a pioneering study using model data to estimate global climatology of environments leading to severe convective storms. Subsequent work has typically focused on regional studies for the United States (Gensini and Ashley 2011; Tippett et al. 2012, 2014; Allen et al. 2015; Gensini and Brooks 2018; Tang et al. 2019; Li et al. 2020; Taszarek et al. 2020b), Australia (Allen et al. 2011; Allen and Karoly 2014; Allen and Allen 2016) Europe (Marsh et al. 2009; Púčik et al. 2017; Rädler et al. 2018; Taszarek et al. 2018, 2019, 2020b), China (Li et al. 2018), southern Africa (Blamey et al. 2017), and South America (Bruick et al. 2019). Global aspects of CAPE, convective inhibition (CIN), and hail environments were also evaluated by Riemann-Campe et al. (2009), Chen et al. (2020), and Prein and Holland (2018). Consistently increasing resolution and quality of environmental sampling have made newer generation reanalysis products more attractive. A recent release of the fifth-generation ECMWF reanalysis (ERA5; Copernicus Climate Change Service 2017; Hersbach et al. 2020) introduced significant improvements in vertical and temporal resolution compared to prior reanalyses such as ERA-Interim, MERRA2, CFSR, and NCEP-NCAR.

Other studies have also focused on specific convective phenomena with the need to improve their forecasting (Thompson et al. 2012; Gropp and Davenport 2018; Anderson-Frey et al. 2018; Coffer et al. 2019). A consistent result between all studies has been the clear dependence of the severity of thunderstorms on the covariate relationship of CAPE and vertical wind shear (Rasmussen and Blanchard 1998; Craven and Brooks 2004; Brooks 2009, 2013; Allen and Karoly 2014; Púčik et al. 2015; Anderson-Frey et al. 2016; Taszarek et al. 2017, 2019; Ingrosso et al. 2020). A notable focus in recent years has been also on high-shear low-CAPE (HSLC) environments with an enhanced potential of producing severe weather, typically during the cold season as evidenced for western and central Europe and the southeastern United States (Sherburn and Parker 2014; Sherburn et al. 2016; Gatzen et al. 2020; Anderson-Frey et al. 2019; Mathias et al. 2019; Celiński-Mysław et al. 2020).

However, Europe and the United States considerably differ in terms of climatological aspects of environments and probabilities for convective initiation (Brooks 2009, 2013; Groenemeijer et al. 2017; Taszarek et al. 2020b). This imbalance implies that defining environments in similar ways to the United States may not be applicable over other parts of the world. Expanding upon the climatological aspects of severe convective storms over Europe and the United States evaluated in the first part of the study (Part I), here we focus on collocated atmospheric environments and their spatial and temporal variability. For this purpose we use ERA5 with a vertical resolution of 137 hybrid-sigma levels and a temporal step of $1 \mathrm{~h}$. Our aim is to evaluate which ambient thermodynamic and kinematic conditions accompany severe convective storms over Europe and the United States, and assess differences between these two regions. In particular, we aim to address the question of why Europe has longer return periods of extreme convective events compared to the United States.

Three aspects differentiate our work from similar prior efforts. First, a larger sample size provides ample opportunity to better characterize convective environments over both continents. Second, the resolution of ERA5 allows us to derive convective profiles with a temporal and vertical resolution that was not possible for prior global reanalyses. The vertical resolution of ERA5 (28 levels up to $2 \mathrm{~km}$ ) is particularly relevant, as parameters such as CIN or CAPE are very sensitive to the number of available levels in the lower troposphere. Finally, integration of hourly lightning data with storm reports and ERA5 collocated environments allows derivation of conditional probabilities for convective events, likelihood of convective initiation, and a fraction of severe environments relative to the overall number of thunderstorms, aspects rarely explored in prior research.

\section{Dataset and methodology}

\section{a. Lightning data}

Lightning data for the United States were derived from the National Lightning Detection Network (NLDN; Cummins and Murphy 2009; Kingfield et al. 2017; Koehler 2020) for a 30-yr period (1989-2018). All cloud-to-ground lightning events (Table 1 ) were aggregated on a $0.25^{\circ}$ grid and 1 -h temporal step to match ERA5. Instead of an absolute flash number, a thunderstorm hour is used, defined by at least two flashes per grid per hour. This technique partially reduces spatial and temporal inhomogeneities that result from changes in network detection efficiency (Cummins and Murphy 2009; Nag et al. 2014). 
Severe weather reports used in the analysis and definition of a conditional probability sub-domain

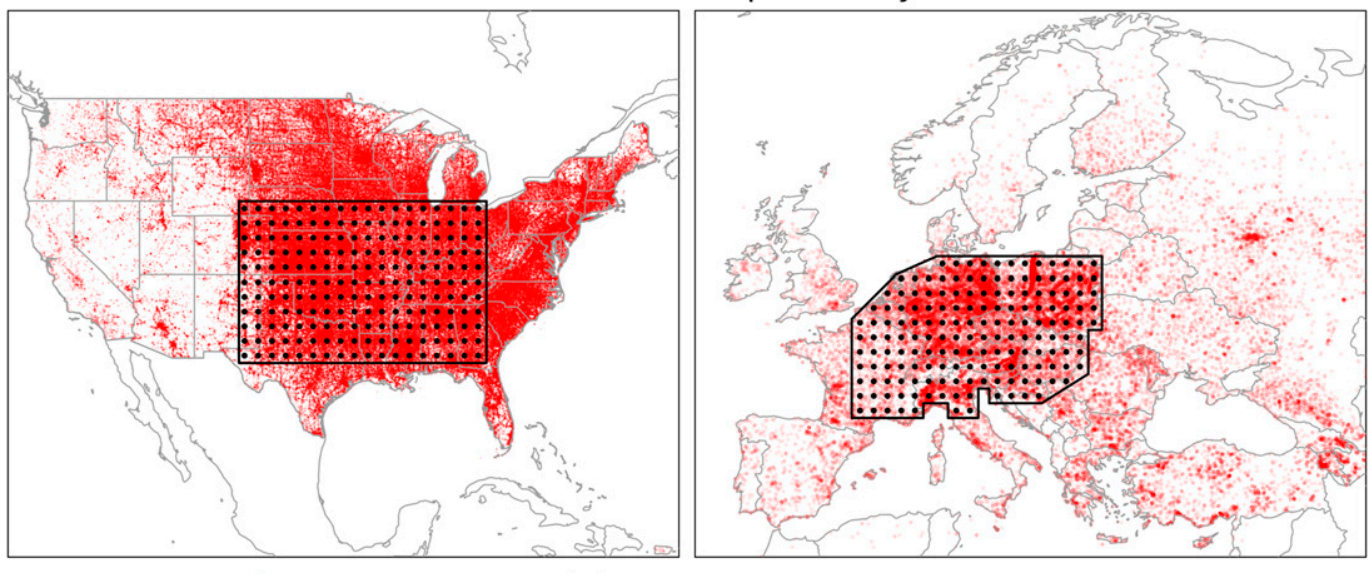

- Sub-domain used for conditional probability estimates

FIG. 1. Severe weather reports for the United States (SPCSD) and Europe (ESWD) from years 1979-2018 used in this study (red circles). Black points denote grid points used for conditional probability estimates.

For Europe, flash data were taken from the Arrival Time Difference long-range lightning detection network (ATDnet; Enno et al. 2020) operated by the Met Office. Analogous to the NLDN all flashes between 2006 and 2018 (Table 1) were aggregated to a $0.25^{\circ}$ grid, and converted to thunderstorm hours. Further details on both NLDN and ATDnet datasets applied here can be found in Part I.

\section{b. Severe weather reports}

Severe thunderstorm reports including tornadoes, large hail, and severe wind (Fig. 1) were extracted from Storm Prediction Center Storm Data (SPCSD; Schaefer and Edwards 1999) and European Severe Weather Database (ESWD; Dotzek et al. 2009). Both datasets were aggregated to $0.25^{\circ}$ grid over the 40 yr period (1979-2018). For tornado reports, all F0 (Fujita 1971) cases occurring over water surface (waterspouts) were excluded. Remaining tornado cases were divided into F0-F1, F2F3, and F4-F5 categories. For large hail, we used only events where the maximum hail diameter was $\geq 2 \mathrm{~cm}$ (with the exception of boxplot analysis where an additional class of marginal $<2 \mathrm{~cm}$ hail was added). All hail events were divided into $2-5,5-8$, and $\geq 8 \mathrm{~cm}$ classes.

Among severe wind events (i.e., "a speed of at least $25 \mathrm{~m} \mathrm{~s}^{-1}$ or one doing such damage that a wind speed of $25 \mathrm{~m} \mathrm{~s}^{-1}$ or higher is likely to have occurred"; Part I), only reports that were associated with lightning activity within $45 \mathrm{~km}$ and $\pm 1 \mathrm{~h}$ were retained. This aimed to exclude severe wind of nonconvective origins, which was frequently the case within ESWD. Due to this filter, severe wind reports match periods of lightning data availability. All filtered severe wind reports were divided into $<32$ and $\geq 32 \mathrm{~m} \mathrm{~s}^{-1}$ peak wind gusts. However, it is worth mentioning that SPCSD contains estimated gusts in addition to measured (Edwards et al. 2018; Part I). Since many prior studies show convective wind gusts can occur in a variety of meteorological conditions with the most frequent division into cold-season (high-shear and low- instability) and warm-season (low-shear and high-instability) environments (Evans and Doswell 2001; Corfidi et al. 2006; Púčik et al. 2015), we divided our cases into warm and cold types based on a $2 \mathrm{~m} \mathrm{AGL}$ temperature (below and over $15^{\circ} \mathrm{C}$, respectively).

To avoid duplication of environments, we took into account only unique events per grid per hour of each category. For example, if four 2-5-cm large hail events were reported within the same grid and 1-h interval, only one unique profile from ERA5 was used. However, if there was a severe weather report of a different category (e.g., tornado) that profile was included for that category as well. In total 818689 severe weather reports associated with unique ERA5 vertical profiles were taken into account. Classification of these into severe and significant severe categories can be found in Table 2. Further details on the quality and inhomogeneity issues of SPCSD and ESWD are described in Part I.

\section{c. Conditional probability subdomains}

To derive conditional probabilities of severe and nonsevere thunderstorms, specified subdomains were defined (Fig. 1). Leveraging our analysis of observed records (Part I) these subdomains cover areas with the best severe weather reporting efficiency and consistent coverage of lightning data. The choice for Europe is framed by the spatial biases of the ESWD dataset toward central Europe where sample size and data quality are maximized. This should be taken into account in interpretation of the results as we do not take into consideration Mediterranean area that feature higher CAPE environments and more frequent storms during autumn. The U.S. subdomain was chosen to match the size of the European region, and coincide with the highest frequency of severe thunderstorms.

In each conditional probability subdomain data were upscaled to a $1.25^{\circ} \times 1.00^{\circ}$ grid (approximately $105 \mathrm{~km} \times$ $111 \mathrm{~km}$ ) to avoid duplication of environments on a local scale. 
TABLE 2. Number of unique ERA5 grid profiles associated with each category.

\begin{tabular}{|c|c|c|c|}
\hline \multirow[b]{2}{*}{ Category } & \multicolumn{2}{|c|}{ No. of unique ERA5 profiles } & \multirow[b]{2}{*}{ Additional note } \\
\hline & Europe & United States & \\
\hline Nonsevere thunderstorm & 584187 & 1844344 & $\begin{array}{l}\text { Lightning events not associated with the } \\
\text { occurrence of any severe weather } \\
\text { report with } \pm 1 \text {-h temporal proximity }\end{array}$ \\
\hline Hail $(<2 \mathrm{~cm})$ & 6860 & 76371 & Used only in boxplot analysis \\
\hline Hail $(2-5 \mathrm{~cm})$ & 9217 & 175670 & Classified as severe \\
\hline Hail $(5-8 \mathrm{~cm})$ & 1582 & 15249 & Classified as significant severe \\
\hline Hail $(\geq 8 \mathrm{~cm})$ & 203 & 1624 & Classified as significant severe \\
\hline Tornado (F0-F1) & 4121 & 34784 & $\begin{array}{l}\text { F0 waterspouts removed } \\
\text { Classified as severe }\end{array}$ \\
\hline Tornado (F2-F3) & 587 & 5282 & Classified as significant severe \\
\hline Tornado (F4-F5) & 6 & 300 & Classified as significant severe \\
\hline Wind $\left(25-32 \mathrm{~m} \mathrm{~s}^{-1}\right)$ (cold) & $4298^{\mathrm{a}}$ & $8848^{\mathrm{a}}$ & $\begin{array}{l}\text { Occurring at } 2 \text {-m temperature }<15^{\circ} \mathrm{C} \\
\text { Classified as severe }\end{array}$ \\
\hline Wind $\left(\geq 32 \mathrm{~m} \mathrm{~s}^{-1}\right)$ (cold) & $391^{\mathrm{a}}$ & $966^{\mathrm{a}}$ & $\begin{array}{l}\text { Occurring at } 2-\mathrm{m} \text { temperature }<15^{\circ} \mathrm{C} \\
\text { Classified as significant severe }\end{array}$ \\
\hline Wind $\left(25-32 \mathrm{~m} \mathrm{~s}^{-1}\right)$ (warm) & $11758^{\mathrm{a}}$ & $258021^{\mathrm{a}}$ & $\begin{array}{l}\text { Occurring at } 2-\mathrm{m} \text { temperature } \geq 15^{\circ} \mathrm{C} \\
\text { Classified as severe }\end{array}$ \\
\hline Wind $\left(\geq 32 \mathrm{~m} \mathrm{~s}^{-1}\right)$ (warm) & $293^{\mathrm{a}}$ & $20392^{\mathrm{a}}$ & $\begin{array}{l}\text { Occurring at } 2 \text { - } \mathrm{m} \text { temperature } \geq 15^{\circ} \mathrm{C} \\
\text { Classified as significant severe }\end{array}$ \\
\hline
\end{tabular}

${ }^{\mathrm{a}}$ Filtered only to cases associated with lightning activity ( $\pm 1-\mathrm{h}$ proximity).

All severe weather reports and lightning detections were assigned to the nearest grid in 1-h steps. Thunderstorm hours (at least two flashes) with no severe weather reported within \pm 1 -h proximity were considered as nonsevere thunderstorms. If severe weather was reported, the thunderstorm was assigned as severe or significant severe. To ensure an environment is representative of an event, time steps of $\pm 1 \mathrm{~h}$ were also labeled to this category to avoid misclassification. For example, classifying the hour before or after an F4 tornado as nonsevere would decrease our ability to contrast nonsevere and (significant) severe environments. The conditional probability subdomains were also used to estimate return periods of specific hazards. To address noise within the conditional probability phase spaces, smoothing in the form of a $3 \times 3$ grid moving window was applied. Grids with a very low number of situations (outliers with less than 0.1 events per year) were removed from these plots.

\section{d. Reanalysis and convective variables}

ERA5 has a $0.25^{\circ}$ horizontal grid spacing with 137 terrainfollowing hybrid-sigma model levels, which contrasts many earlier studies that have used no more than 37 pressure levels for parcel computations. For both the European and the U.S. domains a total of 25.4 billion vertical profiles for 1979-2018 were processed to derive descriptive thermodynamic and kinematic parameters. For each ERA5 profile, temperature, humidity, pressure, geopotential, and $U$ and $V$ wind were vertically interpolated. For parcel calculations, a surface to $500 \mathrm{~m}$ above ground level (AGL) mixed layer (ML) was used while also applying a virtual temperature correction (Doswell and Rasmussen 1994). For storm-relative helicity computations, the internal dynamics method (Bunkers et al. 2000) was applied. The choice of convective parameters evaluated in this study was based on prior work concerning severe thunderstorm environments over both Europe and the United States (Brooks et al. 2003; Groenemeijer and van Delden 2007; Kaltenböck et al. 2009; Gensini and Ashley 2011; Thompson et al. 2012; Púčik et al. 2015; Taszarek et al. 2017). Formulas that were used to compute supercell composite (SCP), significant tornado (STP), and significant hail (SHIP) parameters are available in appendix A. To compare with prior work, we also use a composite product of instability and vertical wind shear, specifically, a square root of 2 times CAPE multiplied by $0-6-\mathrm{km}$ wind shear (WMAXSHEAR; Taszarek et al. 2017, 2018, 2019).

Convective parameters derived from ERA5 profiles were assigned to corresponding severe weather reports and thunderstorm hours by a spatial $\left(0.25^{\circ}\right.$ spacing $)$ and temporal (1-h step) proximity. The latter differs from the majority of prior studies using reanalysis and sounding observations, where data resolution was typically limited to temporal proximity of $6 \mathrm{~h}$.

\section{e. Limitations}

The quality of severe weather data, local reporting practices, and spatiotemporal biases that are different over the United States and Europe (Part I) are limitations to our approach. A difference in lightning detection efficiency between ATDnet and NLDN may also introduce minor inhomogeneities in the estimates of thunderstorm hours, and subsequently in collocated environments. Another source of potential bias is in the convective parameters formulated from ERA5. Although it is the most recent reanalysis, its horizontal resolution still requires convective parameterization, which can impact the vertical profile of temperature, moisture, and measures of instability (Allen et al. 2014; Tippett et al. 2014). Reanalyses are also known for producing biases in the lowest portion of the 
a)
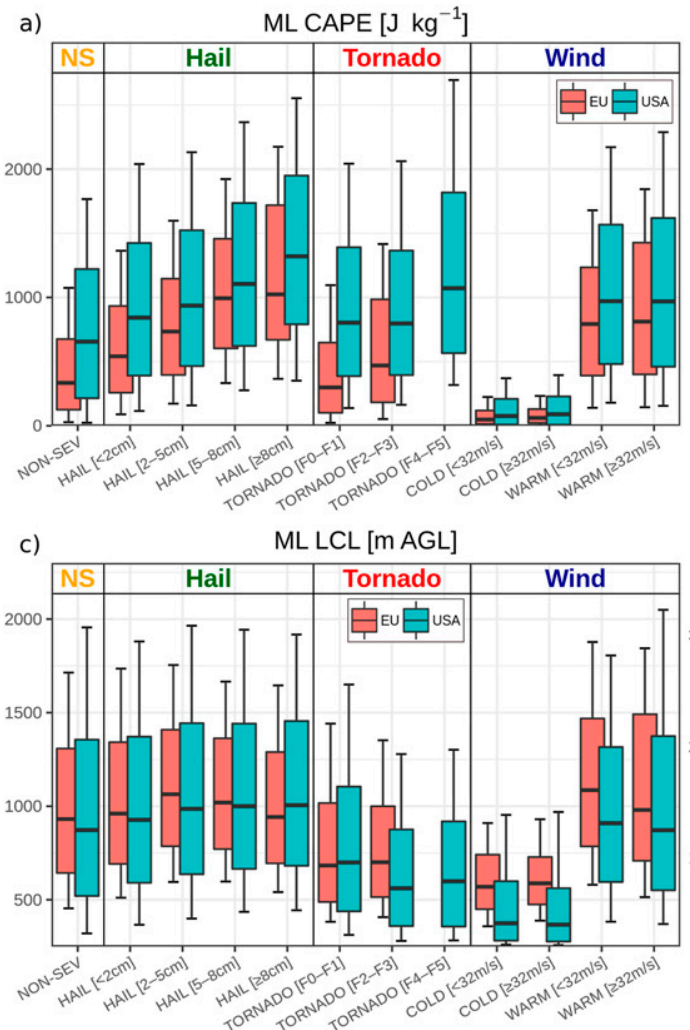

e)

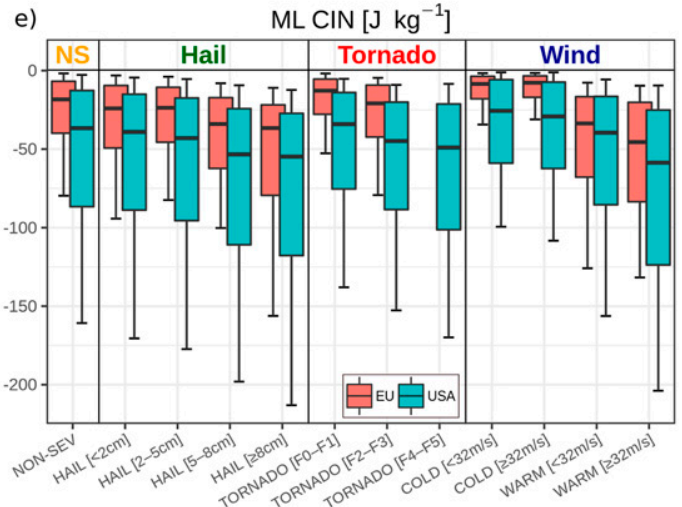

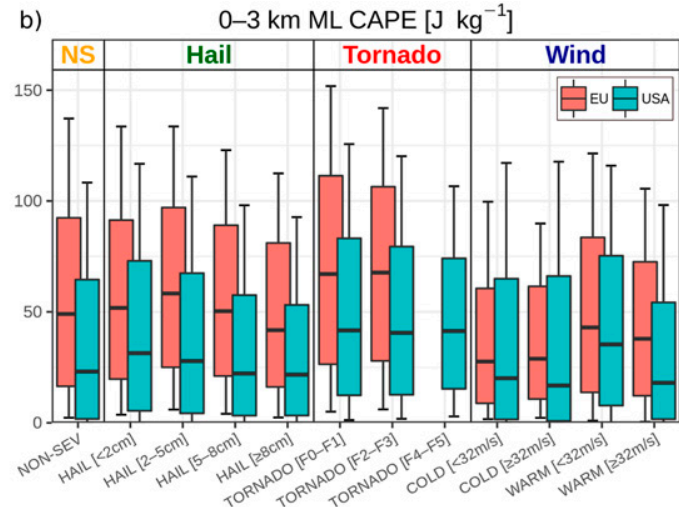

d)

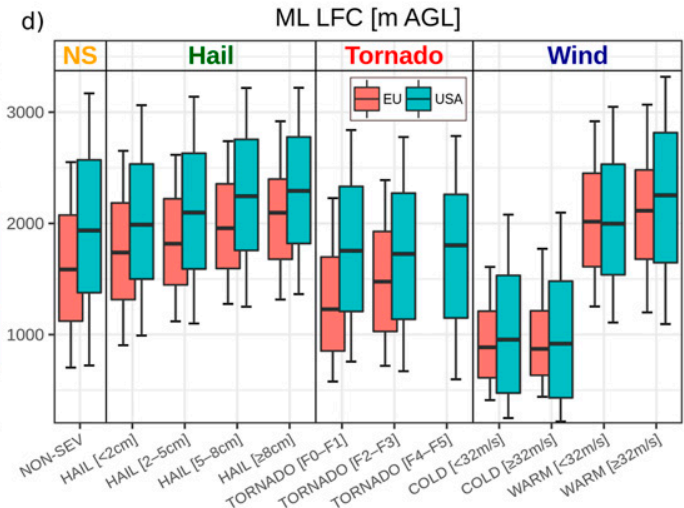

f)

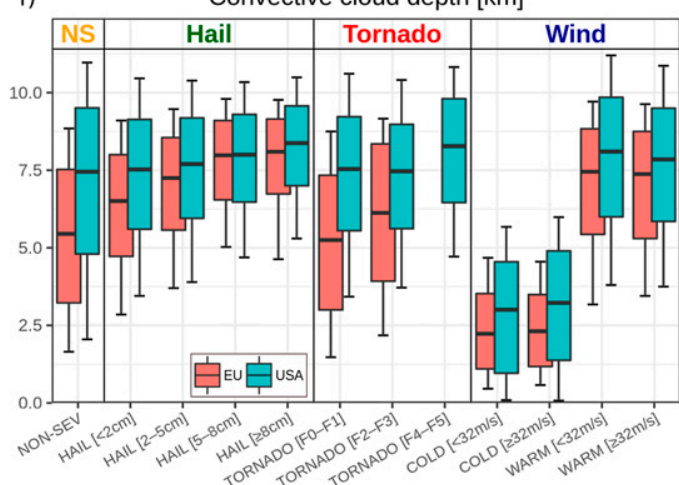

FIG. 2. Box-and-whisker plots of (a) ML CAPE, (b) 0-3-km ML CAPE, (c) ML LCL, (d) ML LFC, (e) ML CIN, and (f) convective cloud depth (ML EL and ML LFC difference). The median is represented as a horizontal line inside the box, the edges of the box represent the 25 th and 75 th percentiles, and whiskers represent the 10th and 90th percentiles. Categories are defined as in Tables 1 and 2. Convective variables are derived from ERA5 proximity grid points.

atmosphere as a result of boundary layer parameterization schemes and data assimilation limitations (Gensini et al. 2014; Allen and Karoly 2014; Taszarek et al. 2018; King and Kennedy 2019; Li et al. 2020). These aforementioned factors may contribute to inaccuracies in representation of convective environments. However, although we are aware that caution should be taken in interpretation of the results, by leveraging the large sample size of environments we minimize any individual bias, leaving the main influence to systematic biases in ERA5.

\section{Results}

\section{a. Parcel parameters}

Consistent with prior studies, there is a relationship between increasing CAPE and severity of hail and tornado events (Fig. 2a). However, although the difference in CAPE between nonsevere thunderstorms and F0-F3 tornadoes is not substantial, CAPE is notably higher for $\geq 5$-cm hail events. Severe wind reports show a poor relationship between CAPE and magnitude of peak gusts. However, warm-season cases usually 
a)

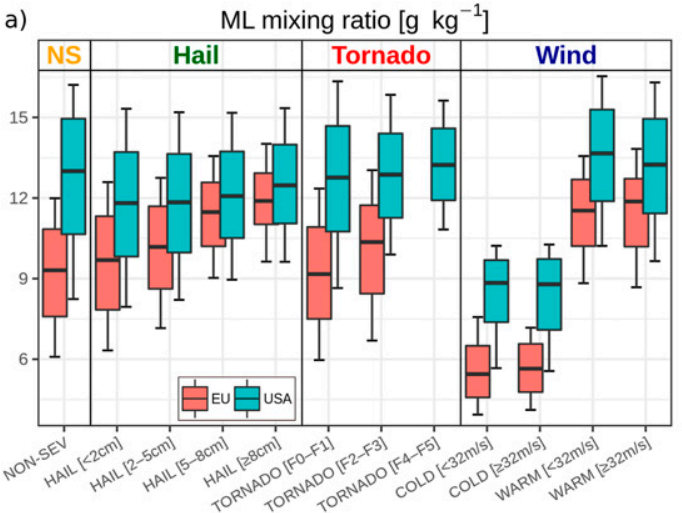

c)

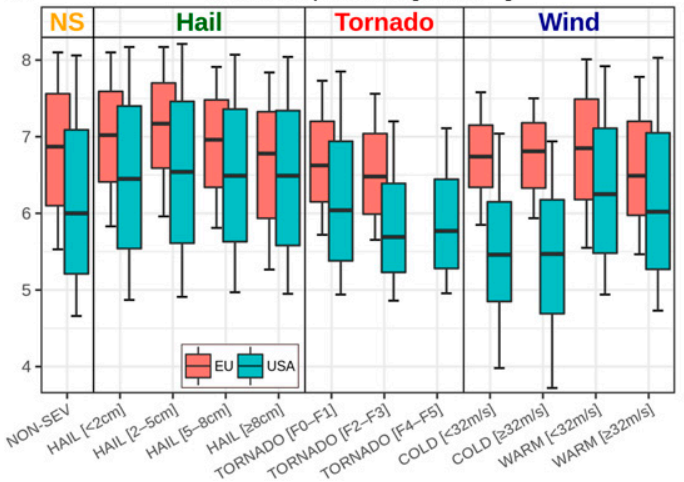

b)

Precipitable water [mm]

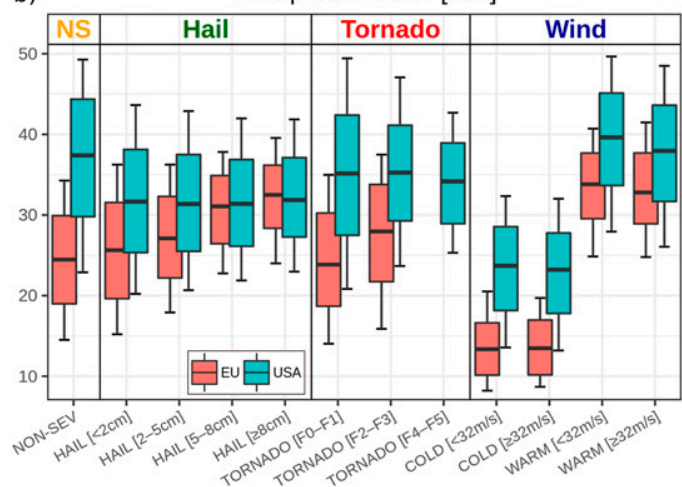

d)

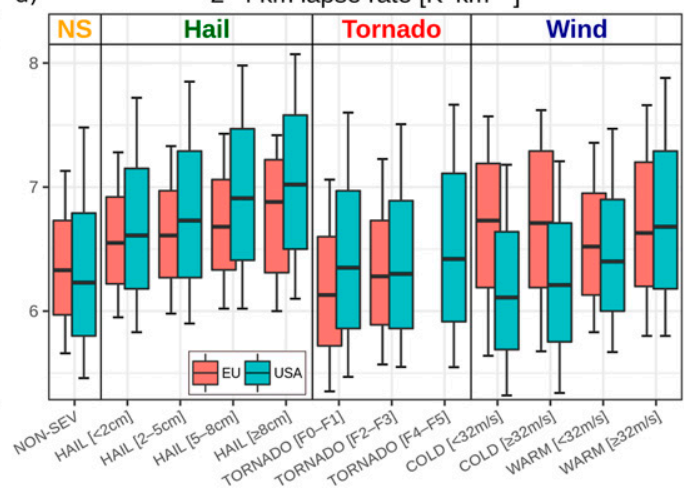

FIG. 3. As in Fig. 2, but for (a) ML mixing ratio, (b) precipitable water, (c) 0-3-km temperature lapse rate, and (d) 2-4-km temperature lapse rate.

have higher CAPE compared to nonsevere thunderstorms. In comparison to other categories, elevated values of $0-3-\mathrm{km}$ CAPE are found for tornadoes, especially across Europe (Fig. 2b). Comparing between the regions, severe and nonsevere thunderstorms over the United States have considerably larger CAPE compared to Europe. However, buoyancy in the $0-3-\mathrm{km}$ layer is greater over Europe, driven by steeper lowlevel lapse rates (Fig. 3c). Greater similarities between the continents are found for lifted condensation level (LCL), which shows more overlap between nonsevere and large hail categories (Fig. 2c) than in Púčik et al. (2015) and Taszarek et al. (2017). However, LCL is a better predictive characteristic for tornadoes (median 600-700 m) and cold-season severe winds. A decreased level of free convection (LFC) is also apparent in these two categories, but unlike LCL, it better distinguishes between hail sizes (Fig. 2d). In addition, LFC over the United States is considerably higher compared to Europe, unlike LCL.

The discrepancy between LCL and LFC reflects CIN, which is considerably stronger over the United States (Fig. 2e). Over Europe, weak CIN allows for a more frequent convective initiation, which compared to the United States results in a higher "severe weather efficiency" (Brooks 2009; Groenemeijer et al. 2017; Taszarek et al. 2020b; see also section $3 \mathrm{f}$ herein). On the other hand, stronger CIN may delay the convective initiation till the CAPE is maximized and allow for discrete convective modes including isolated supercells, which are known for producing very large hail and tornadoes across the Great Plains (Smith et al. 2012; Thompson et al. 2012, 2013). The isolation of convective mode may partially explain why CIN increases along with increasing severity of large hail (Fig. 2e). Considerable CIN reported in some fraction of severe weather events over the United States may also suggest that elevated convection modes are also being represented within this dataset.

Consistent with high CAPE, thunderstorms over the United States have higher convective cloud depths (difference between height of LCL and EL), and this parameter has overall poor skill in distinguishing between nonsevere and severe categories (Fig. 2f). However, it is notable that some fraction of tornadoes over Europe occur in a shallow, low-topped convection that may be related to HSLC mini-supercells (Davies 1993) or weak and short-lived non-mesocyclonic tornadoes. The latter usually form in different environments compared to mesocyclonic tornadoes (Davies 2006), and as a result the weak tornado category in our study may demonstrate a bimodal distribution in certain parameters. Cold-season severe wind events also occur predominantly in a low-topped shallow convection (Fig. 2f), consistent with association of marginal CAPE.

\section{b. Moisture and lapse rates}

Evaluation of both low-level (mixing ratio; Fig. 3a) and vertically integrated (precipitable water; Fig. 3b) moisture indicate considerable differences between European and U.S. 
a)

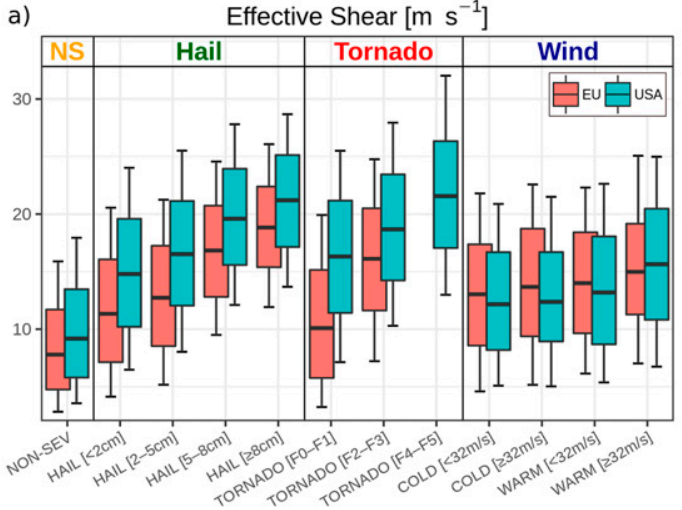

c)

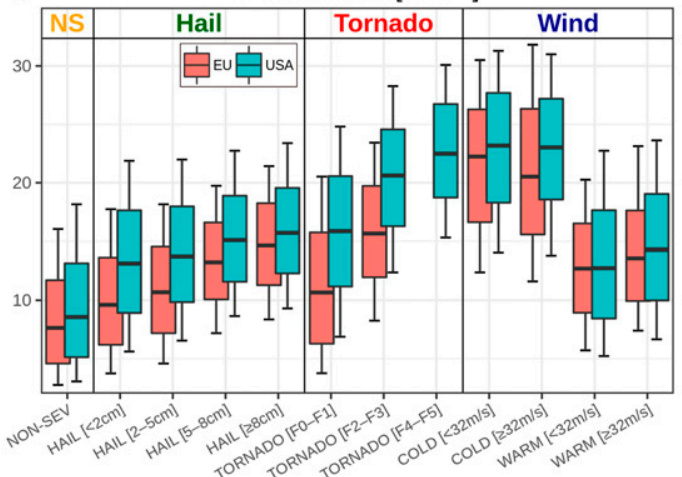

e) $\quad 0-3 \mathrm{~km}$ storm-relative helicity $\left[\mathrm{m}^{2} \mathrm{~s}^{-2}\right]$

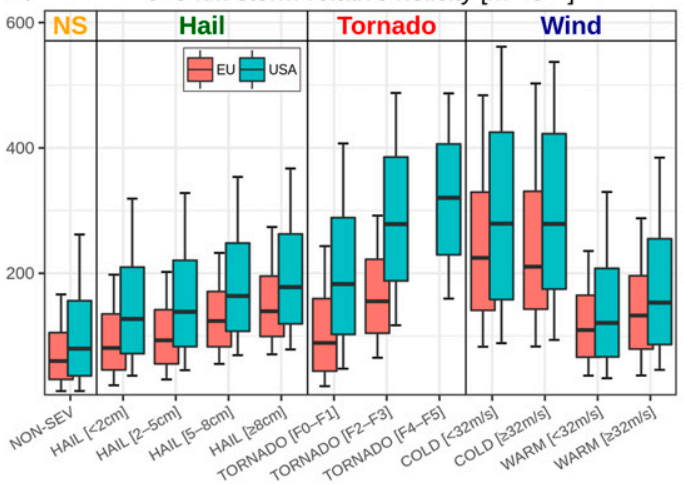

b)

$0-6 \mathrm{~km}$ shear $\left[\mathrm{m} \mathrm{s}^{-1}\right]$

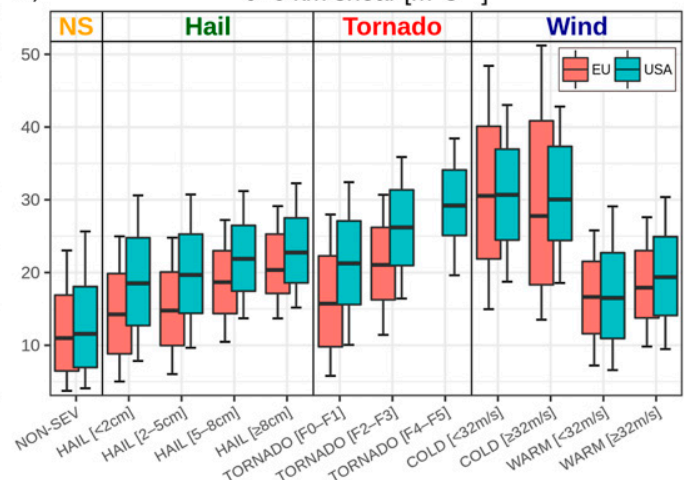

d)

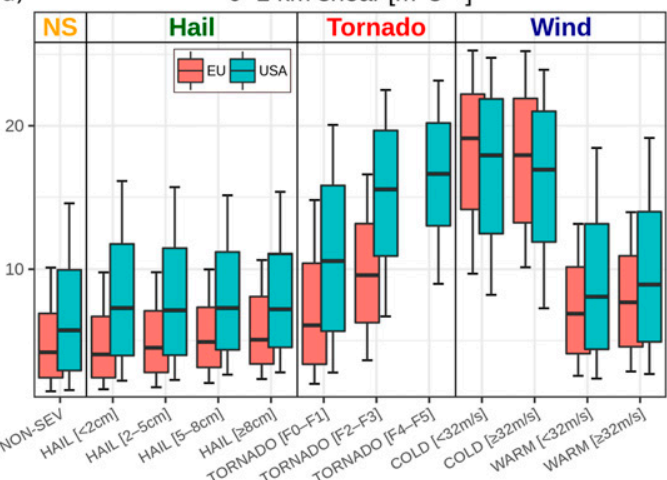

f) Low level jet (1-3 km AGL mean wind) $\left[\mathrm{m} \mathrm{s}^{-1}\right]$

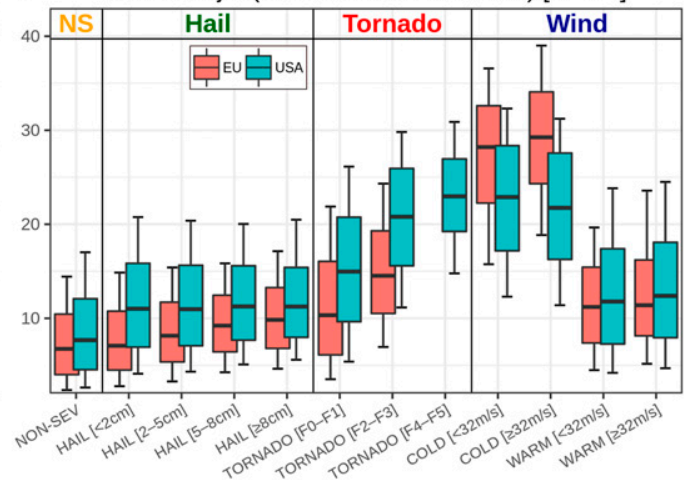

FIG. 4. As in Fig. 2, but for (a) effective shear, (b) 0-6-km wind shear, (c) 0-3-km wind shear, (d) 0-1-km wind shear, (e) $0-3-\mathrm{km}$ storm-relative helicity, and (f) low-level jet (as a 1-3-km mean wind).

environments. For the nonsevere category, the 25th percentile for the United States is equivalent to the 75 th percentile for Europe. Similar differences in moisture between domains are also found for tornadoes and severe wind gusts. This pattern is not apparent for large hail reports, particularly for $\geq 5-\mathrm{cm}$ hail, suggesting ample moisture to be a necessary ingredient. Increasing moisture content generally favors increasing hail size, especially when low levels are considered (Fig. 3a). Another observation is that violent (F4-F5) tornadoes over the United States occur in slightly lower precipitable water compared to weaker tornadoes, which may be linked to excessive cold pools being less supportive of tornadogenesis (Markowski et al. 2002). Conversely, enhanced lower tropospheric moisture can reduce evaporative cooling, and improve low-level buoyancy. Low-level (0-3 km) lapse rates (Fig. 3c) are considerably higher over Europe, consistent with results for 0-3-km CAPE (Fig. 2b). Although it may be concluded that large hail events occur typically in higher $0-3-\mathrm{km}$ lapse rates compared to nonsevere thunderstorms, this parameter has no relation to hail size. Midtropospheric lapse rates $(2-4 \mathrm{~km})$ are more similar between Europe and the United States (Fig. 3d). Consistent for both regions, severe weather events feature typically higher midlevel lapse rates, which is unsurprising given their relation to CAPE and updraft strength. However, 
a)

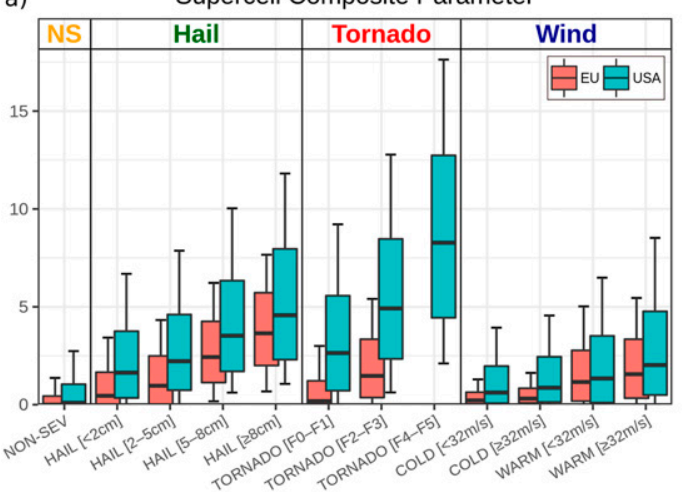

c)

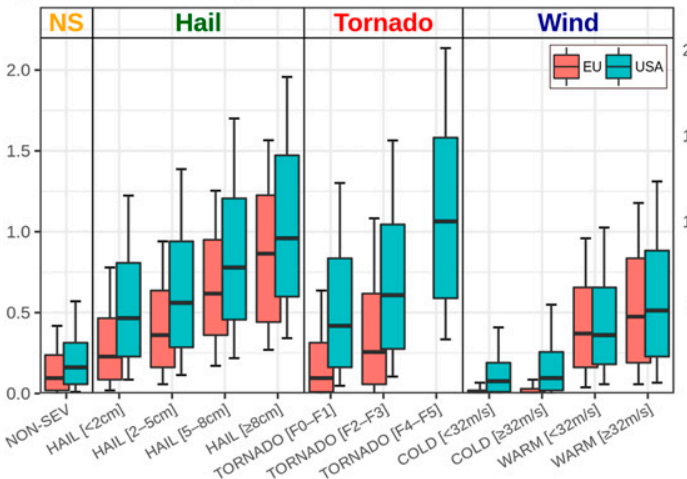

b)

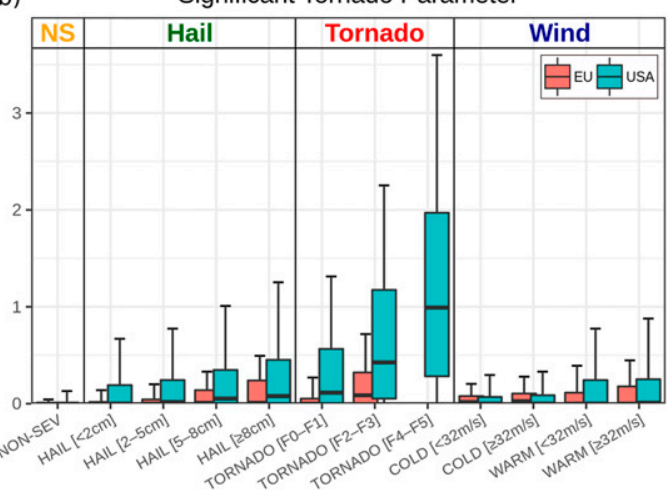

d)

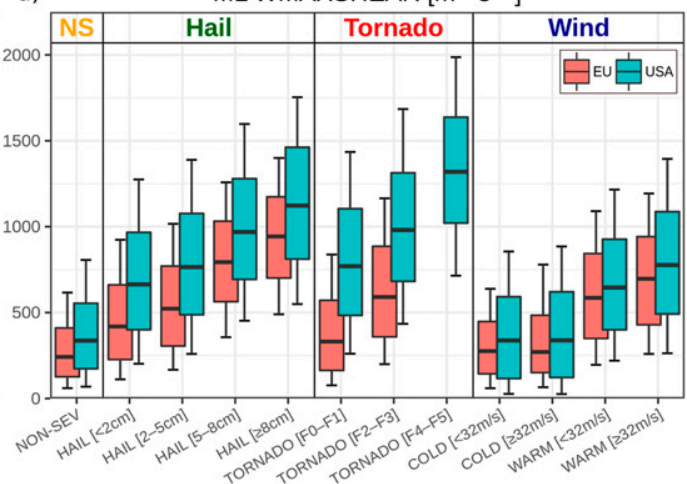

FIG. 5. As in Fig. 2, but for the (a) supercell composite parameter, (b) significant tornado parameter, (c) significant hail parameter, and (d) ML WMAXSHEAR.

disagreement between the two continents can be found for cold-season severe winds (Fig. 3d). Higher lapse rates over Europe may be linked to synoptic patterns that support wintertime windstorm events (Gatzen et al. 2020; Celiński-Mysław et al. 2020). Typically in those situations, eastwardly traveling deep troughs with polar or Arctic air masses allow for the development of steep lapse rates and marginal CAPE over western and central Europe (Kolendowicz 2012; Wapler and James 2015; Piper et al. 2019; Mathias et al. 2019).

Discrepancies between low- and midlevel lapse rates for both domains can be also explained by the presence of an elevated mixed layer (EML) over the United States (Carlson and Ludlam 1968; Banacos and Ekster 2010). An EML typically forms over the high arid terrain of northern Mexico, the southwestern United States, and the Rocky Mountains, and is advected by southwesterly flow over the Great Plains and Midwest. Conversely, at low levels the high values of mixing ratio and higher relative humidities result in low-level lapse rates that are closer to moist adiabatic. Over Europe, EML development is confined to the Iberian Peninsula, the Alps, Turkey, and northwestern Africa (Carlson and Ludlam 1968) and is comparatively rare without a favorable southerly wind component. However, so-called Spanish plume events displacing EML from the Iberian Peninsula are typically linked to severe weather outbreaks over western Europe (Hamid 2012; Mathias et al. 2017; Antonescu et al. 2018).

\section{c. Wind parameters}

Strong vertical shear has long been associated with both convective organization and a corresponding severity (Brooks et al. 2003; Trapp et al. 2007; Allen et al. 2011; Brooks 2013; Púčik et al. 2015; Taszarek et al. 2017). Increasing severity is observed for each category with an increased magnitude of vertical wind shear parameters (Fig. 4). For large hail events effective shear (Thompson et al. 2007) has the best skill in discriminating between nonsevere thunderstorms and $\geq 5-\mathrm{cm}$ hail events. However, effective shear poorly captures coldseason severe wind reports (Fig. 4a), likely related to shallow convective cloud depths (Fig. 2f), on which this parameter strongly depends. Increased shear also leads to larger updraft area in the hail growth region, permitting longer trajectories and thus larger sizes (Kumjian and Lombardo 2020). Bulk wind shear for the 0-6-, 0-3-, and 0-1-km layers better distinguishes between nonsevere thunderstorms and tornadoes, especially those having a rating of F2 + (Fig. 4). However, the 0-3-km version discriminates better among tornado intensity, especially considering violent F4-F5 storms (Fig. 4). This parameter also shows better performance than the strength of low-level jet or storm-relative helicity, which can be surprising as the streamwise vorticity in the lowest few hundred meters has been found to be a crucial ingredient for tornadogenesis in idealized numerical simulations (Coffer and Parker 2018). 
Cold-season severe wind events are also better captured by fixed-layer wind parameters, although there is no relationship to intensity. However, while wind shear in cold-season cases is large, CAPE at the same time is marginal (Fig. 2a). This is consistent with prior studies on HSLC environments (Sherburn and Parker 2014; Anderson-Frey et al. 2019) that have been shown to have an enhanced potential for producing severe winds (Mathias et al. 2019; Gatzen et al. 2020; Celiński-Mysław et al. 2020). Patterns for severe weather categories in 0-1-km stormrelative helicity (not shown) and low-level jet (as 1-3-km mean wind) are very similar to those of $0-3$ - and $0-1-\mathrm{km}$ wind shear (Fig. 4). However, cold-season wind events occur typically with a stronger low-level jet over Europe, while storm-relative helicity and $0-1-\mathrm{km}$ wind shear is considerably larger over the United States. Considering all categories, it can be concluded that thunderstorms with effective shear exceeding $15 \mathrm{~m} \mathrm{~s}^{-1}, 0-3-\mathrm{km}$ shear exceeding $15 \mathrm{~m} \mathrm{~s}^{-1}$, and $0-6-\mathrm{km}$ shear exceeding $20 \mathrm{~m} \mathrm{~s}^{-1}$ are likely to be associated with severe weather.

\section{d. Composite indices}

Composite indices utilize the interrelationship between a number of convective parameters to improve on the forecast skill of any individual parameter (Brooks et al. 2003). Here we consider the distributions of four commonly used operational forecasting parameters; SCP, STP, SHIP, and WMAXSHEAR (Fig. 5). Common to each of these indices is inclusion of instability and shear parameters, often with calibrations to a set of known cases or conditional requirements. As a result, each parameter is capable of distinguishing between nonsevere, severe, or specific phenomena environments. For example, by design STP is highly skilled at discriminating between F2+ tornadoes and other severe weather categories (Fig. 5b). However, its calibrating threshold means it is more effective across the United States (Grams et al. 2012; Thompson et al. 2013; Hart and Cohen 2016; Gensini and Bravo de Guenni 2019). Over Europe, significant tornadoes occur in lower CAPE and storm-relative helicity (Figs. 2a and 4e), which means that STP is not as effective in predicting significant tornadoes. Performance of SCP, SHIP, and WMAXSHEAR is very similar despite different numbers of components building these indices (Fig. 5). Each index features increasing values along with increasing intensity of convective hazards. However, similar to STP calibrating thresholds of SCP and SHIP mean that they are more effective across the United States. WMAXSHEAR is close to universally applicable for both European and the United States, with the added advantage of being a combination of only two variables that captures much of the signal (Brooks 2013; Taszarek et al. 2017). Hereafter, we focus on WMAXSHEAR to study the climatological aspects of severe thunderstorm environments in the further part of the paper. In addition, an analysis of ERA5 convective precipitation and lightning flash rates as severe thunderstorm proxies is provided in appendix B.

\section{e. Conditional probabilities}

Combining severe weather reports and lightning detection data over both Europe and the United States enables estimation of conditional probability of severe weather, which has not been yet compared between the continents. Based on

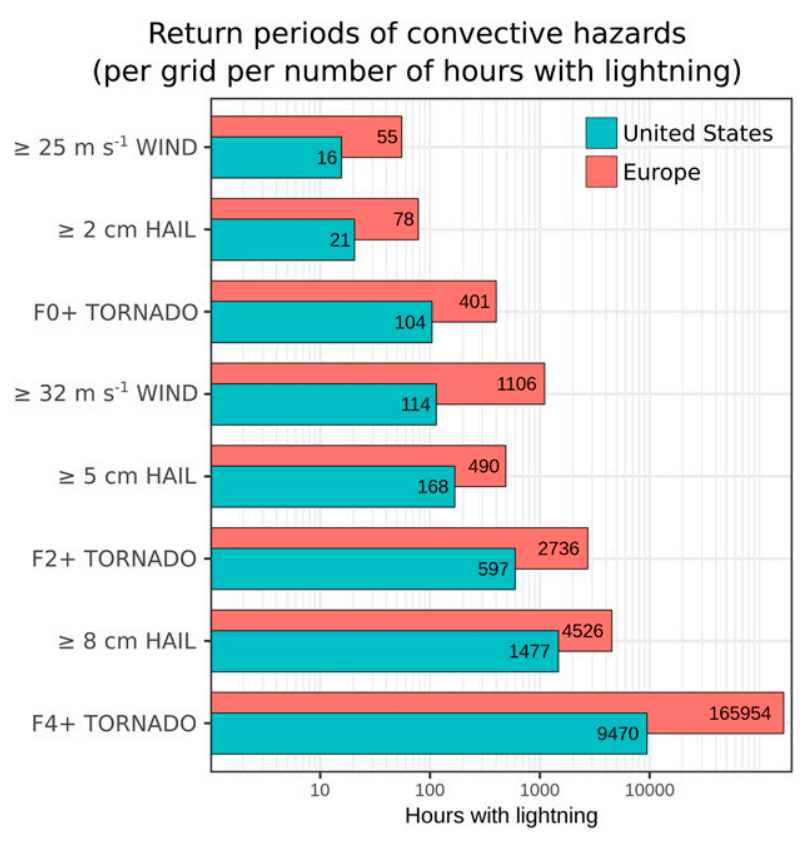

FIG. 6. Return periods of certain convective events relative to the number of hours with lightning (please note logarithmic scale). These estimates are derived from conditional probability subdomain grids (Fig. 1) and cover a comparable period of 2006-18 for both Europe and the United States.

subdomains presented in Fig. 1, conditional return periods of convective hazards given thunderstorm hours were estimated. The most common storm hazards are $\geq 25 \mathrm{~m} \mathrm{~s}^{-1}$ severe wind and $\geq 2$-cm hail. Such events are reported once every 16 and 21 thunderstorm hours respectively over the United States (Fig. 6). For Europe both of these events require around 3-4 times the number of thunderstorm hours. F0 + tornadoes, $\geq 32 \mathrm{~m} \mathrm{~s}^{-1}$ severe wind gusts, and $\geq 5$-cm hail events occur on average every 104, 114, and 168 thunderstorm hours over the United States, whereas they are considerably less frequent over Europe (401, 1106, and 490 thunderstorm hours). Strong tornadoes (F2+) are very rare events over both continents, with return periods of 597 and 2736 thunderstorm hours respectively (Fig. 6). However, $\geq 8$ $\mathrm{cm}$ large hail events are around twice as rare over both domains (1477 and 4526h). For the extremely infrequent violent tornadoes $(\mathrm{F} 4+)$, these events have a return interval of 9470 thunderstorm hours over the United States, whereas over Europe that estimate is 17 times higher and only individual cases are reported per decade (Fig. 6).

Considering all hazards, the relative frequency over Europe is typically 3-4 times lower than across the United States. Explanation for this reduced probability is showcased by the phase space of two skillful severe thunderstorm predictors, CAPE and 0-6-km shear, and their resulting combination of WMAXSHEAR (Figs. 7-10). Climatologically, the occurrence of favorable instability-shear parameter phase space is much more frequent over the United States (Figs. 7a and 8a). This is especially evident for CAPE, where the tail of the distribution for Europe is $3000-4000 \mathrm{~J} \mathrm{~kg}^{-1}$, compared to $6000-8000 \mathrm{~J} \mathrm{~kg}^{-1}$ over the United States (Fig. 7a). However, after cross-validating 
Climatology and conditional probability for lightning, severe and sig. severe thunderstorm (given ML CAPE and 0-6 km wind shear over Europe and the United States)
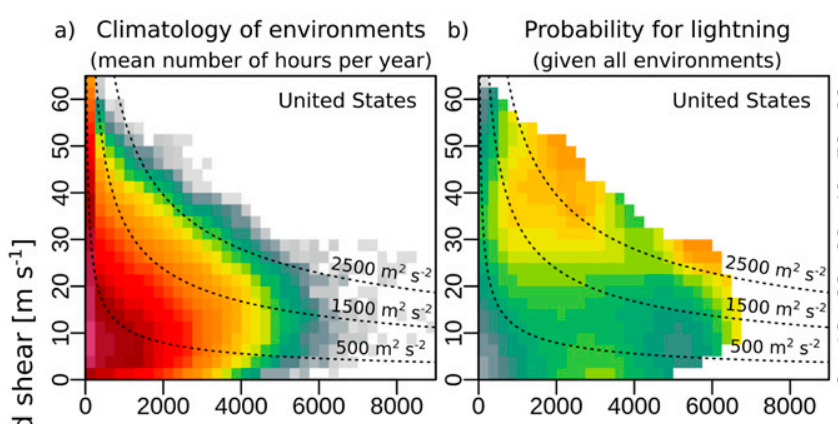

c) Probability for any severe (given lightning)

d) Probability for any sig. severe (mean number of hours per year)
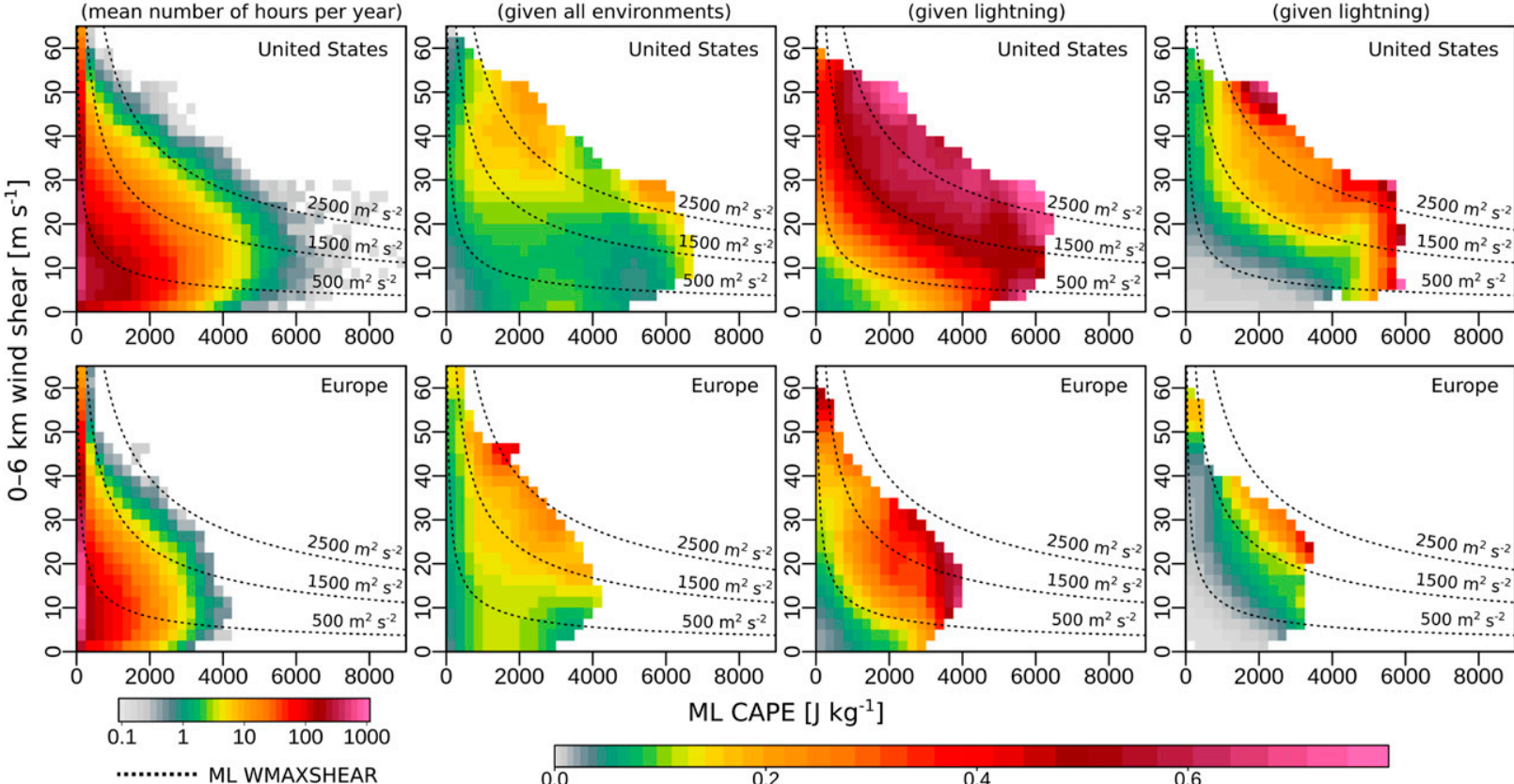

FIG. 7. (a) Scaled mean number of hours per year, and conditional probability for (b) lightning, (c) any severe thunderstorm, and (d) any significant severe thunderstorm for specific ML CAPE and 0-6-km wind shear parameter space (definitions of severe and significant severe thunderstorms are in Table 2). Dashed lines indicate constant ML WMAXSHEAR values. These estimates are derived from conditional probability subdomain grids (Fig. 1) and cover a period of (bottom) 2006-18 for Europe and (top) 1989-2018 for the United States.

climatological background with lightning events to establish thunderstorm conditional likelihood, Europe has generally higher probability for convective initiation (Figs. 7b and 8a), consistent with Brooks (2009, 2013), Groenemeijer et al. (2017), and Taszarek et al. (2020b). Over both domains probability for lightning increases with increasing values of WMAXSHEAR, especially in a stronger shear environments (Fig. 7b).

Differences between domains are also found for severe (Fig. 7c) and significant severe (Fig. 7d) thunderstorm probabilities. However, European probabilities never reach parts of the parameter space when the likelihood for severe and significant severe thunderstorm rapidly increases in the United States, reflecting the extreme rarity of such environments over Europe, if they occur at all. The difference in severe weather reporting, particularly related to biases and inhomogeneity issues (Part I), may also influence severe thunderstorm probabilities across Europe. Division into specific convective hazards suggests that the largest differences result from the probability of severe wind and 2-5-cm hail events (Figs. 9 and 10). These may be indicative of an underreporting bias in the ESWD for these categories. Stronger and more impactful convective events are more likely to be documented and thus provide a more consistent record over time (Brooks and Doswell 2001; Groenemeijer and Kühne 2014). Confirming this expectation, probabilities for significant severe hail $(\geq 5 \mathrm{~cm})$ and tornadoes $(\mathrm{F} 2+)$ share similarities between both domains, although they are typically restricted to lower CAPE for Europe (Figs. 9 and 10).

These relationships reveal that although probability typically increases in response to increasing instability, severe thunderstorms are more likely to occur when shear is sufficient (e.g., at least $15-20 \mathrm{~m} \mathrm{~s}^{-1}$ ), rather than when CAPE is large but shear is weak $\left(<10 \mathrm{~m} \mathrm{~s}^{-1}\right)$. The only exception to this relationship are warm-season severe wind reports, which have enhanced frequency in high CAPE and weak shear regimes, presumably linked to damaging winds within microbursts (Atkins and Wakimoto 1991). High shear and high CAPE severe winds are more likely to be caused by quasi-linear convective systems (QLCS; Coniglio et al. 2007) including derechos (Corfidi et al. 2016). Cold-season severe winds have also very specific probabilities peaking in HSLC environments that are typical for wintertime cold-narrow-frontal rain bands across western and central Europe (NCFR; Gatzen 2011). Enhanced probability of $\geq 5$-cm hail over Europe occur also in a parameter space with high CAPE and shear of around $10 \mathrm{~m} \mathrm{~s}^{-1}$. These events can be explained by a proximity of mountain ranges where environmental wind shear is enhanced by interaction of the wind field with orography, which is often the case for the Alps (Kunz et al. 2018). However, the limited resolution of ERA5 is unable to 
a) Frequency of environments with lightning (scaled mean number of hours per year)

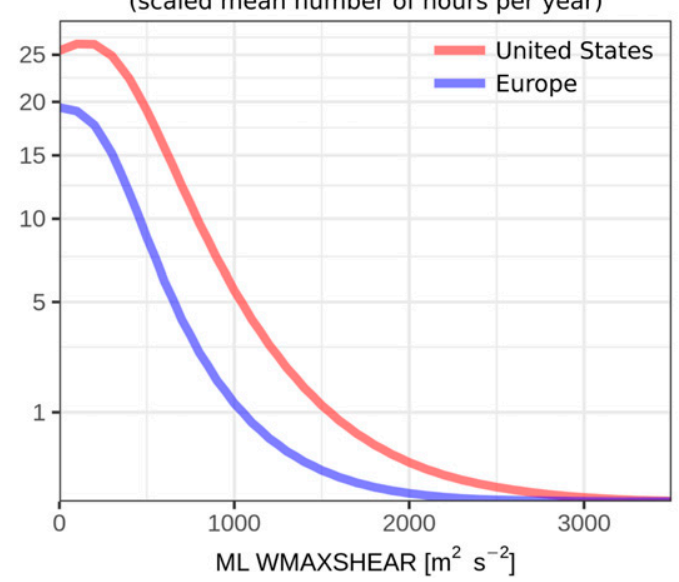

b) Probability for lightning occurrence (given certain ML WMAXSHEAR value)

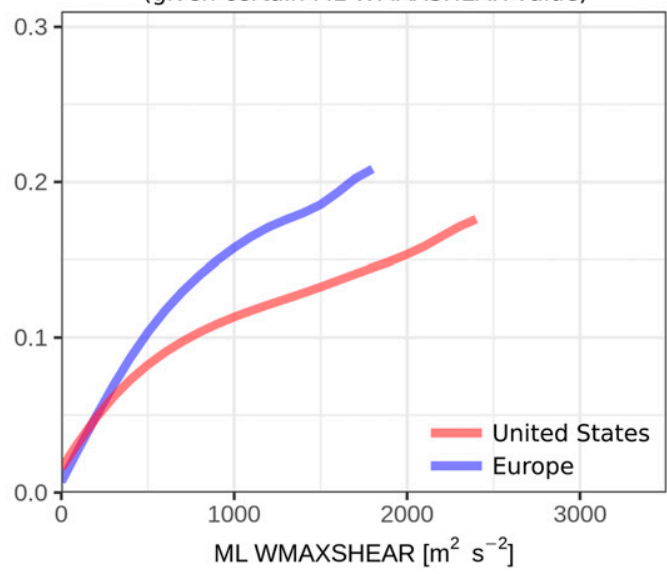

FIG. 8. (a) Scaled frequency of ML WMAXSHEAR environments with lightning and (b) conditional probability for lightning given specific ML WMAXSHEAR values (only for frequency higher than $0.1 \mathrm{yr}^{-1}$ ). These estimates are derived from conditional probability subdomain grids (Fig. 1) and cover a period of 2006-18 for Europe and 1989-2018 for the United States.

represent this enhancement. In general, increasing probability for severe and especially significant severe thunderstorms is captured very well by WMAXSHEAR, which was also noted by Brooks (2013), Taszarek et al. (2017, 2019), and Rodríguez and Bech (2020).

Increased probabilities for weak tornadoes in weak shear situations may be associated with the presence of nonmesocyclonic tornadoes in both ESWD and SPCSD. Since stronger F2 + tornadoes are better captured by low-level wind variables (Fig. 4), we also analyze the climatology and probabilities for WMAXSHEAR and 0-1-km storm-relative helicity parameter space (Fig. 11). Interestingly, where the two distributions have overlap, the probabilities remain fairly similar. However, from the climatological perspective Europe never reaches a parameter phase space of the U.S. environments. This suggests that the main limiting factor for tornadoes over Europe is a lack of sufficient instability under a strongly sheared environment at low levels.

\section{f. Spatial variability}

Another important aspect of severe convective environments is their spatial variability as each geographical region has its own unique features. For comparison to environments, we consider the mean number of thunderstorm hours discussed by Part I with peaks over Florida and mountain ranges (Fig. 12a; see also animation $\mathrm{A}$ in the online supplemental material). However, this pattern is not well correlated with the spatial distribution of severe thunderstorms as these are mainly driven by specific favorable environments (Brooks et al. 2003). Lightning conditional tails of the CAPE distribution (95th percentile; Fig. 12b) indicate peak values along the Gulf of Mexico coast and Florida $\left(>2500 \mathrm{~J} \mathrm{~kg}^{-1}\right)$. However, such storms are typically accompanied by weaker shear regimes, with median 0-6-km shear between 5 and $10 \mathrm{~m} \mathrm{~s}^{-1}$ (Fig. 12c; see supplemental material animation A). A greater degree of instability and shear overlap is unsurprisingly found over the Great Plains corridor (>2250 $\mathrm{J} \mathrm{kg}^{-1} \mathrm{CAPE}$ and $15-20 \mathrm{~m} \mathrm{~s}^{-1} 0$ $6-\mathrm{km}$ shear), especially where shear is more available farther north (Figs. 12a and 12b; see supplemental material animation A). Condition tail distributions of WMAXSHEAR over the entire Great Plains exceed $1100 \mathrm{~m}^{2} \mathrm{~s}^{-2}$ (Fig. 12d; see supplemental material animation B), which based on results from Fig. $5 \mathrm{~d}$ is highly supportive for extremely severe thunderstorms. This result is consistent with prior work (Brooks et al. 2003; Gensini and Ashley 2011; Thompson et al. 2013; Li et al. 2020) and overlaps well with large hail and tornado reporting peak densities evaluated in Part I.

European environments are less extreme. Although peak thunderstorm frequency is observed over southern Europe (Fig. 12a), the conditional 95th percentile of CAPE of around $1000-1750 \mathrm{~J} \mathrm{~kg}^{-1}$ stretches from France, through central Europe, into western Russia (Fig. 12b; see supplemental material animation A). Similar values are also observed over the central Mediterranean and Italy. Enhanced shear is observed mainly over the Mediterranean basin, western, southern, and parts of central Europe (Fig. 12b; supplementary material animation A). The distribution of WMAXSHEAR highlights that the highest potential for severe thunderstorms over land occurs over France, Germany, and Italy (95th percentile of WMAXSHEAR $>800 \mathrm{~m}^{2} \mathrm{~s}^{-2}$; Fig. 12c; supplemental material animation B). However, compared to Italy the frequency of thunderstorms is much lower over France and Germany (Fig. 12a).

To estimate potential for extremely severe thunderstorms we use the conditional 99th percentiles of SCP, SHIP, and STP composite parameters as a rough proxy (Fig. 13). Results for both SCP and SHIP are broadly consistent with a spatial distribution of WMAXSHEAR, with lower magnitudes particularly over the Southeast and a bias toward the northern Great Plains for SCP. The pattern for STP is different with peak 


\section{Conditional probability for a certain convective event over the United States} (given ML CAPE and 0-6 km wind shear, and only for situations with lightning)
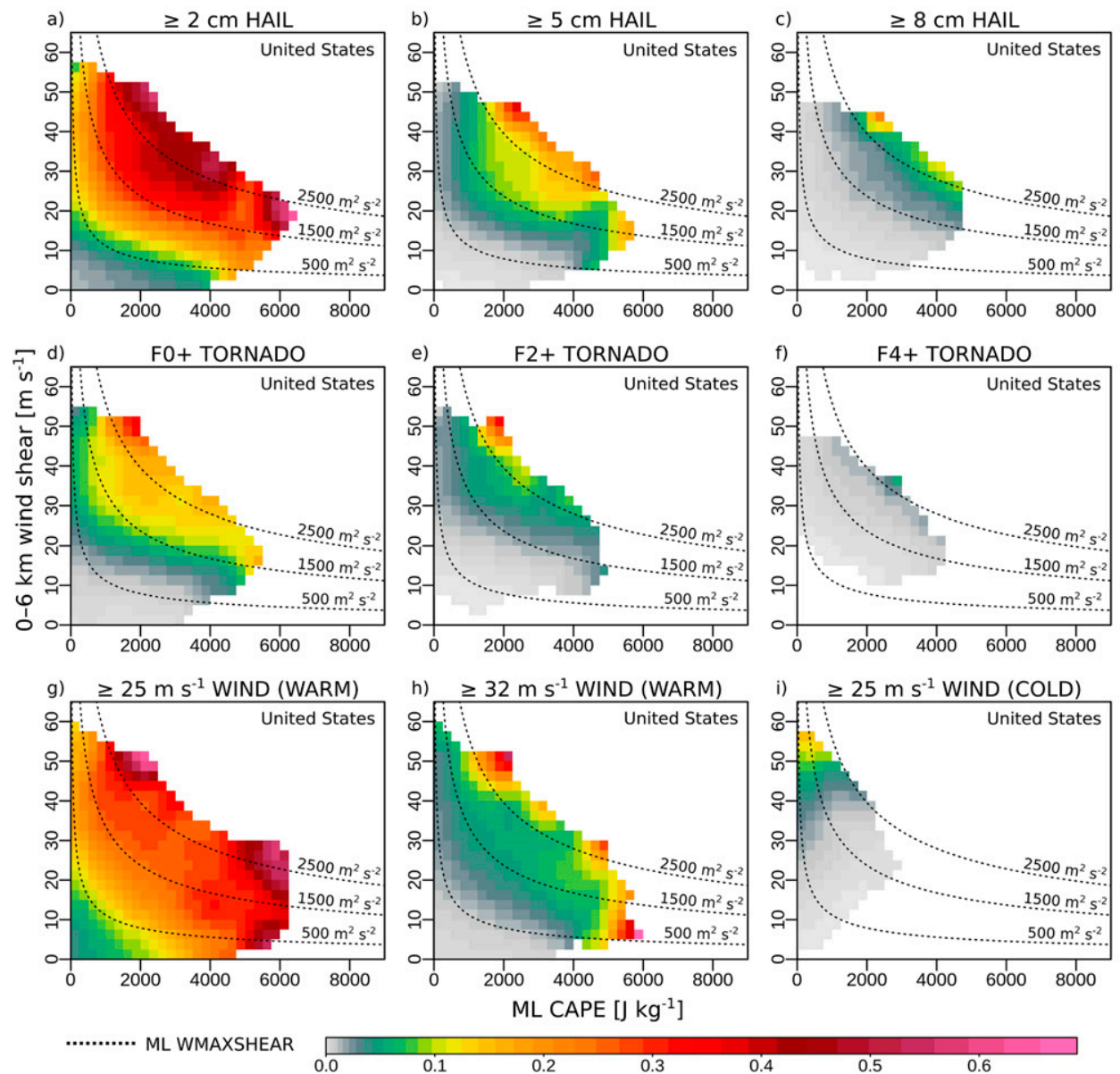

FIG. 9. Conditional probability given ML CAPE and 0-6-km wind shear parameter space as in Fig. 7, but for (a) $\geq 2$-cm hail, (b) $\geq 5$-cm hail, (c) $\geq 8$-cm hail, (d), F0+ tornados, (e) F2 + tornados, (f) F4+ tornados, (g) $\geq 25 \mathrm{~m} \mathrm{~s}^{-1}$ warm-type wind, (h) $\geq 32 \mathrm{~m} \mathrm{~s}^{-1}$ warm-type wind, and (i) $\geq 25 \mathrm{~m} \mathrm{~s}^{-1}$ cold-type wind for Europe. Dashed lines indicate constant ML WMAXSHEAR values.

values observed over the southern Great Plains and western portions of Southeast. Over Europe highest STP is found over the central Mediterranean and northwestern Russia, consistent with increased occurrence of significant tornadoes over these areas (Miglietta and Matsangouras 2018; Chernokulsky et al. 2019, 2020; Ingrosso et al. 2020). Enhanced values of SCP, SHIP, and STP found in a corridor from central France to western Germany also correspond with the location of major severe weather outbreaks (Hamid 2012; Mathias et al. 2017; Antonescu et al. 2018), which can be linked to Spanish plume synoptic patterns (Carlson and Ludlam 1968). However, these values are notably lower compared to the Great Plains, again indicating a considerably lower potential for significant severe thunderstorms over Europe.

Viewed another way, we consider the conditional statistics of severe thunderstorm environments. Leveraging results from this and prior studies (Brooks et al. 2003, 2007; Groenemeijer et al. 2017; Taszarek et al. 2019; Rodríguez and Bech 2020;
Taszarek et al. 2020b), we identify these environments when WMAXSHEAR $>500 \mathrm{~m}^{2} \mathrm{~s}^{-2}, \mathrm{CAPE}>150 \mathrm{~J} \mathrm{~kg}^{-1}$, and $0-6-\mathrm{km}$ wind shear $>10 \mathrm{~m} \mathrm{~s}^{-1}$. Applying this proxy in combination with lightning data indicates that the highest annual number of severe environments with the observed convective initiation occur over the southern Great Plains $\left(>30 \mathrm{~h} \mathrm{yr}^{-1}\right)$, with 10$30 \mathrm{~h}$ over the central and eastern United States (Fig. 14a). Over Europe peak values are observed over northeastern Italy $(>25 \mathrm{~h})$ and coastal zones of the Mediterranean (15-25h), while the remainder of the continent has generally less than $10 \mathrm{~h} \mathrm{yr}^{-1}$.

Evaluating the likelihood of convective initiation, given a severe environment, Europe has probability of around 7\%$12 \%$ over the central and eastern regions (Fig. 14b). In contrast, across the United States, probabilities are slightly lower over the eastern half of the continent $(6 \%-8 \%)$, whereas over the Great Plains this efficiency drops to between $3 \%$ and $6 \%$ (Fig. 14b). Efficiency is the highest over the Rocky Mountains 
Conditional probability for a certain convective event over Europe (given ML CAPE and 0-6 km wind shear, and only for situations with lightning)
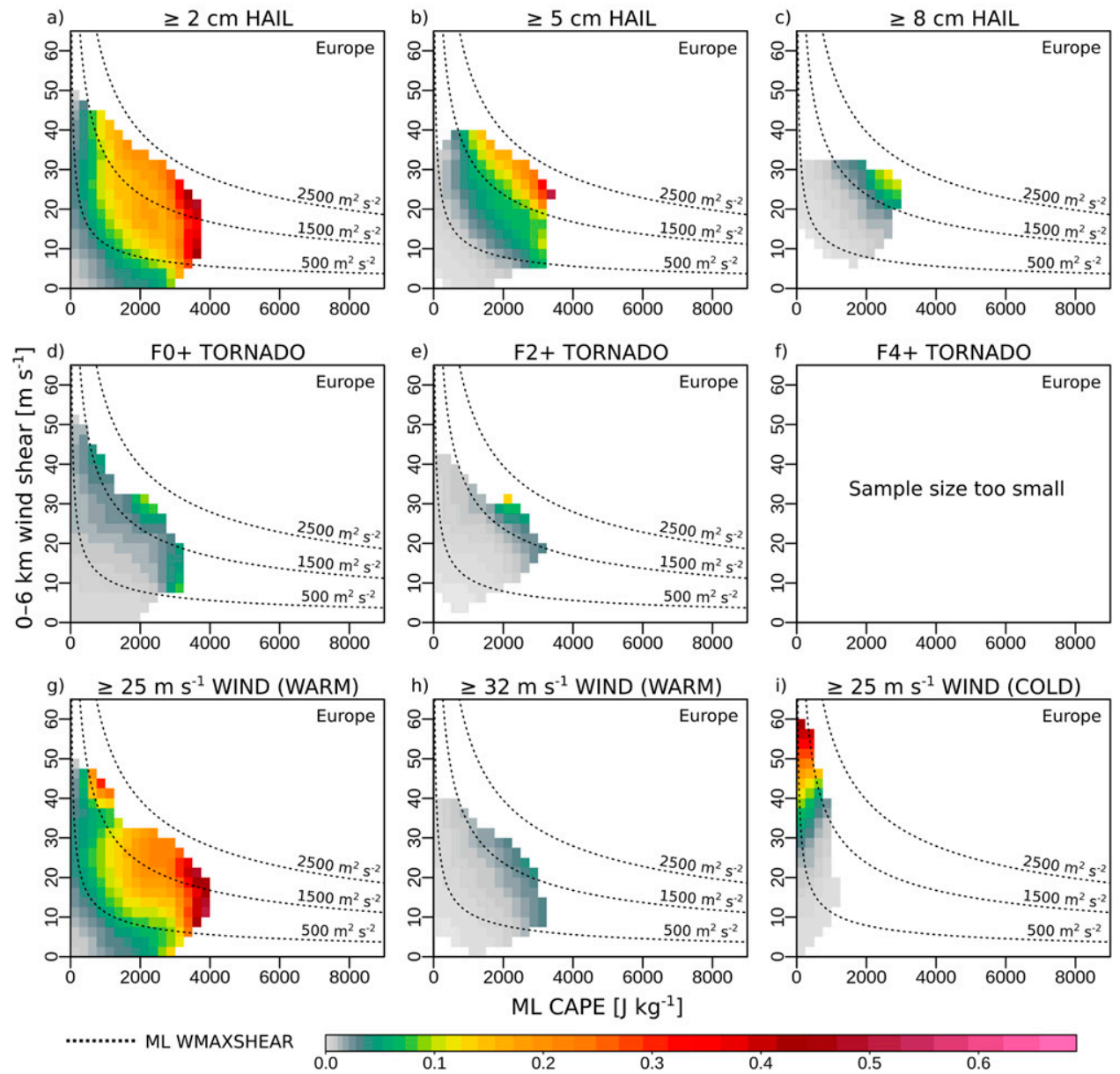

FIG. 10. As in Fig. 9, but for the United States.

$(>12 \%)$; however, in these areas the absolute frequency of severe environments is marginal. Similarly enhanced convective initiation probabilities are also found over mountain areas across Europe (Alps, Carpathians). The lowest probabilities are found over the Mediterranean $(1 \%-4 \%)$.

Finally, we also assess what is the probability of any initiating storm to be associated with severe environment (Fig. 14c). The United States generally has fractional probabilities of $20 \%-30 \%$ over the majority of the central and eastern part of the country. Peak values exceeding $35 \%$ occur over the northern potions of the Great Plains (Fig. 14c). Comparatively, fractions over Europe are much lower, between $5 \%$ and $20 \%$ with peaks over the west and south, suggesting that thunderstorms over Europe are not only less frequent, but also have considerably lower potential of producing severe weather.

\section{g. Diurnal and annual variability}

The hourly resolution of ERA5 provides the opportunity to study diurnal cycles of convective parameters over the length of its record. We use the conditional probability domain
(Fig. 1) and filter using thunder hours to produce annual and diurnal cycles. Peak frequency for lightning over both domains occur between May and August in the early afternoon (1400 UTC) for Europe and slightly later (1600 CST) over the United States (Fig. 15a; supplemental material animation A). Although annual distribution correlates relatively well with CAPE, diurnal variability indicates peak values of instability shifted by around $2-3 \mathrm{~h}$ prior to peak for lightning (1100 UTC for Europe and 1300 CST for the United States). Magnitude differences for the 95th-percentile CAPE between the domains are large, with the United States doubled compared to Europe despite similar timing (Fig. 15b; supplemental material animation A). Wind shear in the layer $0-6 \mathrm{~km}$ is also considerably different, with more consistently strong shear throughout the spring and fall across the United States, but smaller during the summer (Fig. 15c; supplemental material animation A). The diurnal cycle of $0-6-\mathrm{km}$ wind shear has a poor variability during the winter, whereas during summer it has a clearly defined nocturnal peak.

Over the United States, instability rapidly increases during spring when shear is still relatively high. As a result 
Climatology and conditional probability for F2+ TORNADO (given ML WMAXSHEAR and 0-1 km storm-relative helicity)

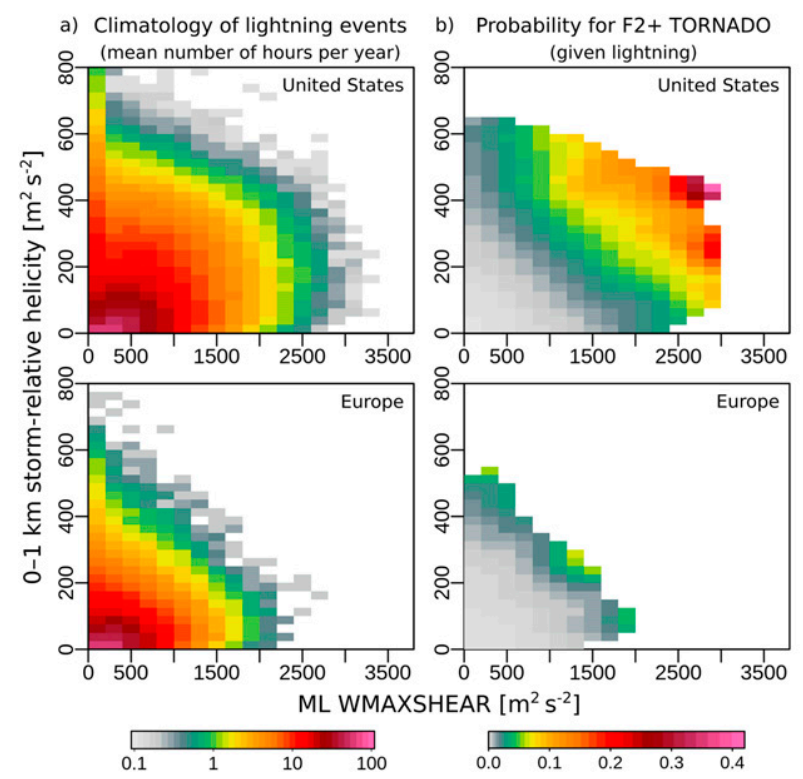

FIG. 11. (a) Scaled mean number of hours per year with lightning and (b) conditional probability as in Fig. 7, but for significant tornados $(\mathrm{F} 2+)$ given specific ML WMAXSHEAR and $0-1-\mathrm{km}$ storm-relative helicity parameter space.

highest WMAXSHEAR is observed between March and May and 1400-2000 CST (Fig. 15d; supplemental material animation B), consistent with observations of the peak probability for convective hazards (Part I). A similar signal can be observed during fall (October-November), but with decreased magnitude. Across Europe WMAXSHEAR peaks in June-September between 1600 and 2000 UTC (Fig. 15d; supplemental material animation B). Another observation is that while severe thunderstorm potential is tied to the summer in Europe, over the United States it is present all year round (but in different locations). In addition to WMAXSHEAR, in appendix $\mathrm{C}$ we also provide annual and diurnal variability for 99th percentile of SCP, SHIP, and STP.

Low-level wind shear $(0-1 \mathrm{~km})$ has the lowest values during summertime and daytime, with a rapid increase toward the nocturnal period associated with the reduction in boundary layer mixing (Fig. 15e). Over the United States, $0-1-\mathrm{km}$ wind shear is notably higher compared to Europe, which is at least partly explainable by the occurrence of the low-level jet (Shapiro et al. 2016), especially during spring and summer. The largest differences between the domains occur in April and May, coinciding with increased tornado activity over the United States. CIN shows a well-defined annual and diurnal cycle, with a much stronger peak value. Weakly capped environments conditional on the presence of lightning are observed between 1000 and 1700 CST over the United States during spring and summer and between 0900 and 1800 UTC over Europe during summer and late spring (Fig. 15f). Following the onset of convection in the afternoon, convective inhibition over the United States increases by 0000 CST with stronger capping resulting in a greater likelihood of elevated convection (Fig. 16d).

Large differences between the annual cycle of both domains are found for low-level moisture (mixing ratio), which has a rather poor variability throughout the day (Fig. 16a). Weak diurnal variability is also observed for midtropospheric lapse rates across Europe, although there are large seasonal differences with peak values observed during winter (Fig. 16a). There is a greater diurnal signal for midtropospheric lapse rates across the United States, with a clear nocturnal peak around $0000 \mathrm{CST}$ and during summer. Conversely, 0-3-km lapse rates are well correlated with diurnal boundary layer heating, and peak between 1000 and 1500 UTC over Europe and between 1100 and 1600 CST for the United States (Fig. 16c). These lapse rates are also larger over Europe, particularly in the spring and early summer compared to their U.S. counterparts with values maximized in the late summer. Similar variability is also observed for LCL and LFC with notably higher values generally observed over the United States (Figs. 16d,e). Over Europe, LCL peaks between 1200 and 1600 UTC in April-August while the peak in the United States is from 1400 to 1800 CST in JuneSeptember. Consistent with CIN, peak for LFC is shifted nocturnally during late spring and summer over both domains. The lowest LFC occurs typically $1-2 \mathrm{~h}$ before noon (Fig. 16e). The height of the equilibrium level (EL) is well correlated with CAPE indicating shallower convective cloud depths over Europe. Peak values over both regions are observed during July and around noon (Fig. 16f).

\section{Discussion and concluding remarks}

Here we focused on the climatological likelihood of severe convective storm environments and their conditional occurrence given the occurrence of lightning. NLDN and ATDnet lightning data, ERA5 convective environments, and severe weather reports from ESWD and SPCSD were combined on a common grid of $0.25^{\circ}$ and 1-h step for years 1979-2018. This is the first time that such a large dataset on hourly resolution has been used to intercompare thunderstorm environments between Europe and the United States. High vertical resolution available with ERA5, including 28 levels up to $2 \mathrm{~km}$ AGL, also allowed exploration of convective parameters with greater confidence in their fidelity. This is especially important for variables that are sensitive to the number of available levels in a boundary layer such as CAPE, CIN, or $0-1-\mathrm{km}$ wind shear. Analysis yielded several findings, among which the most important are listed below:

- Intensity of convective hazards increases with higher environmental wind shear and instability, especially considering large hail events. Tornadoes are supported by lower cloud bases, enhanced low-level wind shear, and 0-3-km CAPE. Cold-season severe winds are characterized by strong lowlevel atmospheric flow and marginal instability, while warmseason events occur in both weak and strong shear regimes.

- Compared to Europe, convective environments over the United States feature higher moisture, CAPE, CIN, wind shear, LFC, and midtropospheric lapse rates. Conversely, CAPE and lapse rates at $0-3 \mathrm{~km}$ are typically higher over 


\section{Mean distribution of lightning hours and collocated environments}

a)

Annual mean number of hours with lightning (at least 2 flashes)

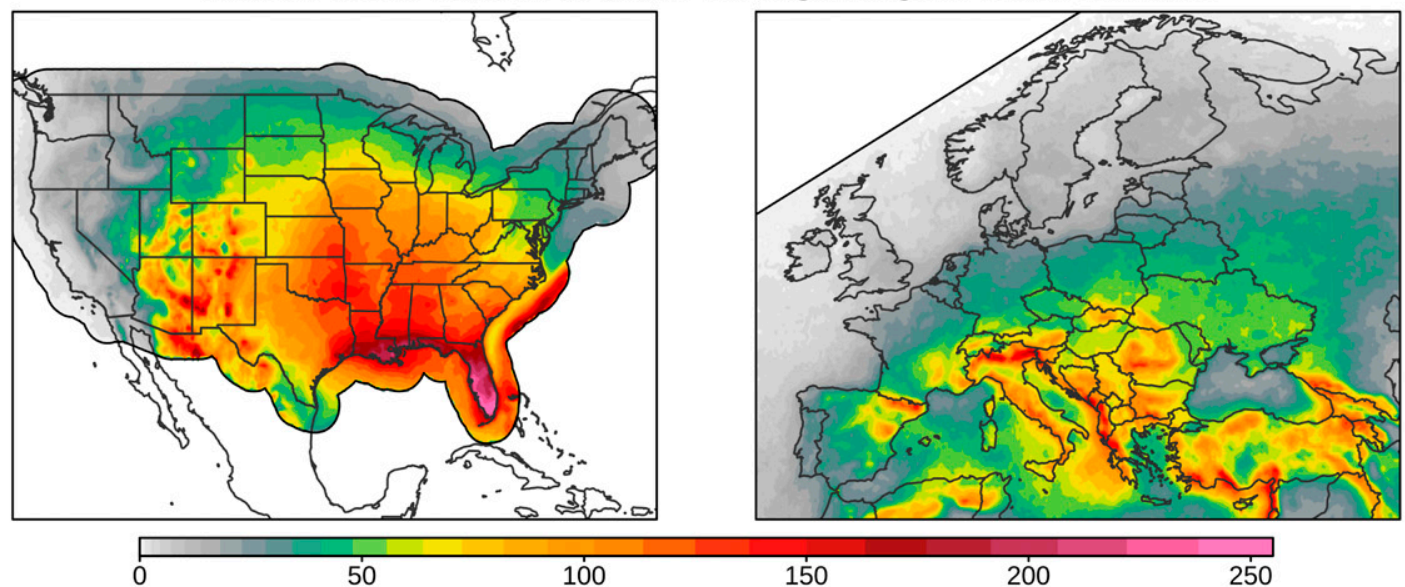

b) $95^{\text {th }}$ percentile of ML CAPE $\left[\mathrm{kg}^{-1}\right]$ (only for lightning events)

c) $50^{\text {th }}$ percentile of $0-6 \mathrm{~km}$ wind shear $\left[\mathrm{m} \mathrm{s}^{-1}\right]$ d) $95^{\text {th }}$ percentile of ML WMAXSHEAR $\left[\mathrm{m}^{2} \mathrm{~s}^{-2}\right]$

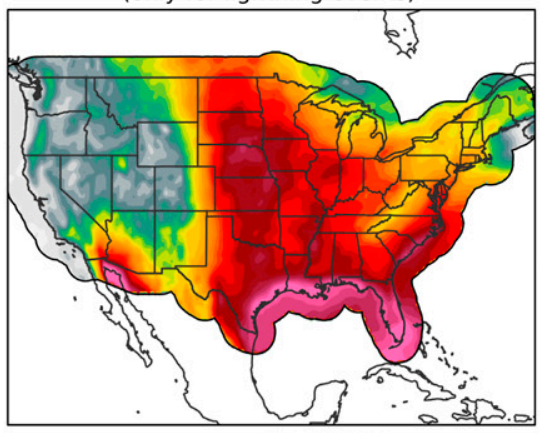
(only for lightning events) (only for lightning events)
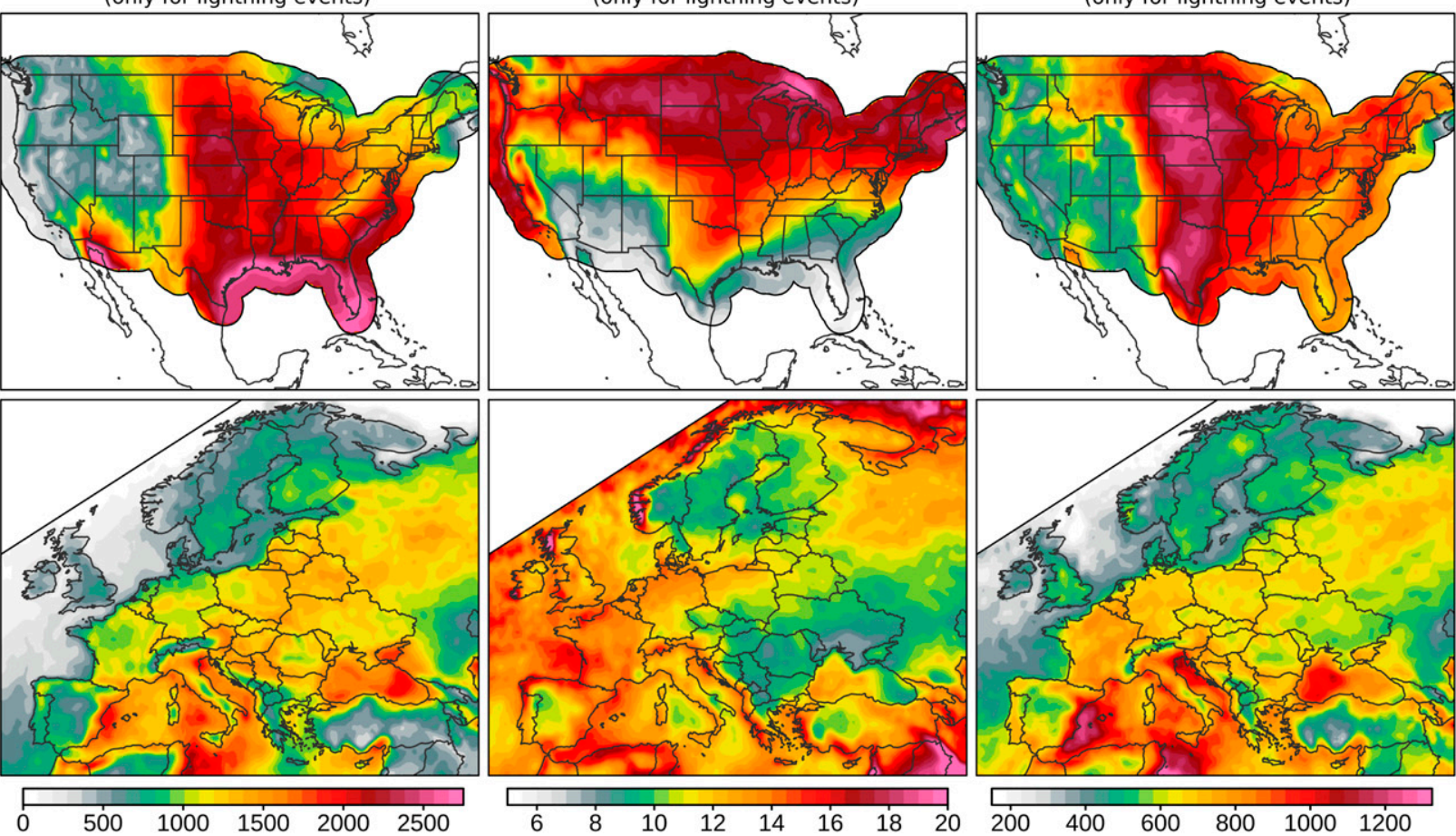

FIG. 12. (a) Annual mean number of hours with lightning (at least two flashes), (b) 95th percentile of ML CAPE, (c) 50th percentile of 0-6-km wind shear, and (d) 95th percentile of ML WMAXSHEAR. Parameters in (b)-(d) are derived only for situations with lightning activity (ATDnet during 2006-18 for Europe and NLDN during 1989-2018 for the United States).

Europe, reflecting low-level profiles that are considerably less moist, and hence characterized by more extreme gradients.

- Among composite parameters WMAXSHEAR is most likely to represent overall thunderstorm severity (especially considering significant severe events). SCP, STP, and SHIP as calibrated parameters are found to typically produce better results over the United States where they were originally designed. However, over Europe in specific situations these parameters can be useful as well.

- Return periods of specific convective hazards are notably shorter over the United States (by a factor of 3-4). Giant $(\geq 8 \mathrm{~cm})$ hail and violent $\mathrm{F} 4+$ tornadoes are the rarest phenomena, while severe convective wind gusts are the most common thunderstorm hazard. 


\section{Tail distribution of composite parameters during lightning}

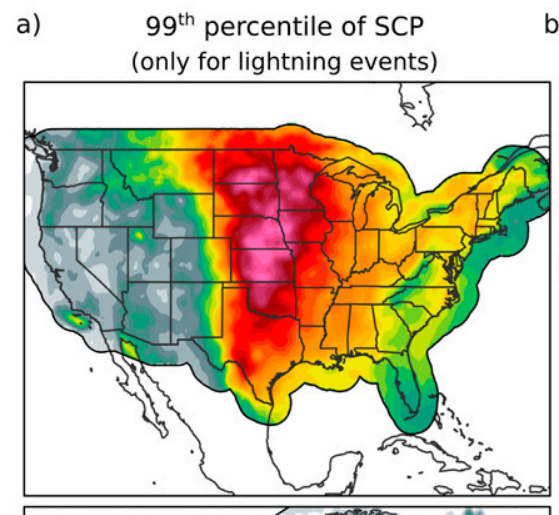

b)

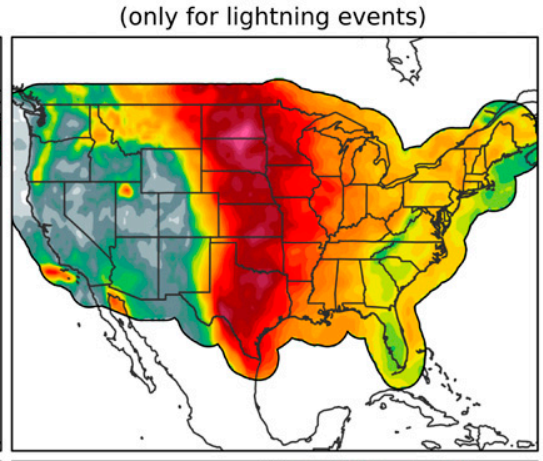

c)

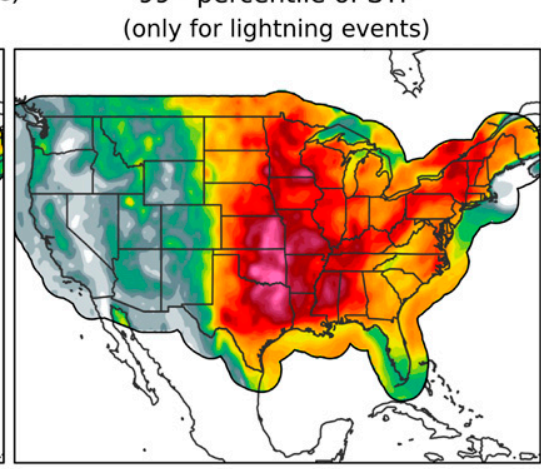

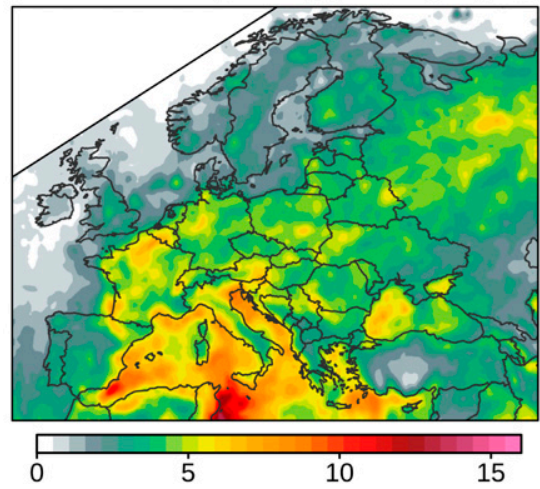
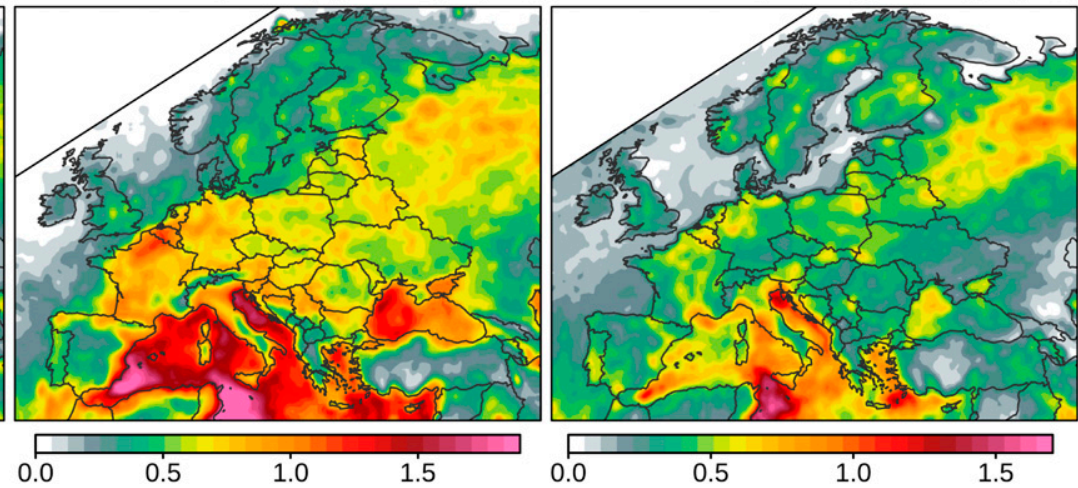

FIG. 13. As in Fig. 12b-d, but for the (a) 99th percentile of supercell composite parameter, (b) 99th percentile of significant hail parameter, and (c) 99th percentile of significant tornado parameter.

- Thunderstorms over Europe are not only less frequent but also have a lower potential for producing severe weather. Limited availability of high CAPE environments combines also with a weaker shear regime compared to the United States. From the climatological perspective favorable severe thunderstorm environments (hours) over the United States are approximately 3-4 times more frequent.

- The most conductive severe thunderstorm environments are observed over the Great Plains, Midwest, and Southeast. Over Europe this corresponds to the south with a peak over northern Italy. Storms over western and central Europe have also enhanced potential for producing severe weather, but they are considerably less frequent as compared to Italy.

- Thunderstorms over Europe have higher probability for convective initiation given a favorable severe environment. The lowest fraction of initiating environments is observed over the Great Plains. However, once a storm forms over that area, there is a higher probability that it will become severe (especially over the northern Great Plains), whereas over Europe these probabilities are considerably lower.

- Diurnal and annual cycles indicate that the prime environmental conditions for severe thunderstorms over the United States occur between April and June, typically from 1200 to
2200 CST, while across Europe the overall likelihood is lower and favorable environments are confined to JuneAugust, usually between 1400 and 2100 UTC.

In part, these results are broadly consistent with prior work on convective environments and their corresponding climatologies over the United States (Rasmussen and Blanchard 1998; Brooks et al. 2003; Trapp et al. 2007; Gensini and Ashley 2011; Thompson et al. 2012, 2013; Tippett et al. 2014; Allen et al. 2015; Li et al. 2020) and Europe (Marsh et al. 2009; Mohr and Kunz 2013; Púčik et al. 2015; Groenemeijer et al. 2017; Taszarek et al. 2017, 2018, 2020b; Rädler et al. 2018; Kunz et al. 2020). However, comparison of observational data with ERA5 provided new insight into environments, particularly when conditioned on the convective initiation (presence of lightning), which has been an ongoing limitation of earlier climatologies. Moreover, the hourly resolution of ERA5 also allowed for a unique investigation of diurnal cycles in convective environments, which was not possible with prior reanalyses. Differences between environments obtained for both continents indicate that some of the variables including composite parameters such as STP may not work as well over Europe as for the United States where instability and low-level wind shear are typically higher. This underlines the importance of either avoiding highly calibrating parameters to the local environment, or instead constructing local convective climatologies using 


\section{Selected characteristics of SEVERE environments*}

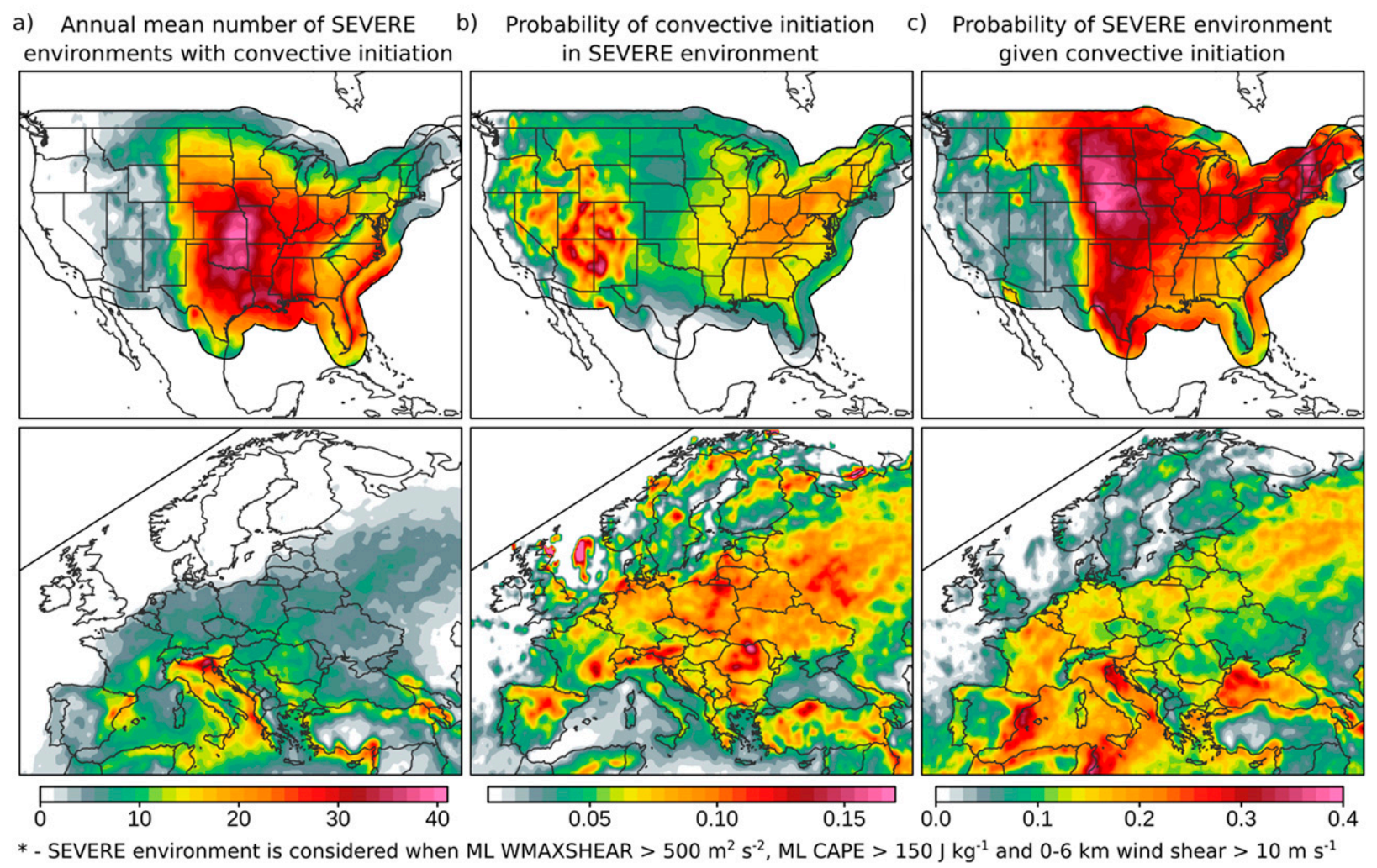

FIG. 14. (a) Annual mean number of situations (in hours) with severe environments and lightning detection (at least two flashes), (b) probability of convective initiation in severe environment (fraction of severe environments associated with lightning), and (c) probability that a developing thunderstorm will be associated with severe environment (fraction of lightning events associated with severe environments). Values are derived from a period of (bottom) 2006-18 for Europe (ATDnet) and (top) 1989-2018 for the United States (NLDN).

parameters that are relevant to the underlying climatological frequency, and not simply applying parameters from the U.S. Great Plains.

An aspect of convective initiation efficiency is also a crucial factor driving convective climatologies. Although the difference in the frequency of unstable environments is very large between Europe and the United States, the disparity in the number of actual thunderstorms is lower (but still considerable). This is because a fraction of unstable environments ending in convective initiation is higher over Europe, compared to the United States, where considerable CIN is occurring. However, more favorable overlap of instability and vertical wind shear over the United States promotes better organization of convection and thus more frequent severe weather as a result, which is broadly consistent with results from Part I. Thus, thunderstorms over Europe are not only less frequent, but have lower potential of producing severe weather. This aspect also explains why Europe has longer return periods of extreme convective events compared with the United States.

Although in this study we used all available severe thunderstorm samples and the most recent reanalysis, prolonging measurement periods of lightning detection networks, more effective collection of storm data, and increasing resolution of the next generation of reanalysis will allow further progress in constructing accurate climatologies. Such efforts are important to understand both the underlying risk associated with severe convective storms and changes that will result from a globally warming climate in the future.

Acknowledgments. This research was supported by grants from the Polish National Science Centre (project number 2017/ 27/B/ST10/00297) and the Polish National Agency for Academic Exchange-The Bekker Programme (project number: PPN/BEK/ 2018/1/00199). J.T. Allen was supported by the National Science Foundation under Grant AGS-1855054. The reanalysis computations were performed in the Poznan Supercomputing and Networking Center (project number 448). We are grateful to the Met Office and NOAA National Severe Storms Laboratory for providing lightning data. The European Severe Storms Laboratory and the Storm Prediction Center are gratefully acknowledged for providing severe weather reports.

Data availability statement. ERA5 data (temperature, specific humidity, geopotential, pressure, $U$ and $V$ vectors) were downloaded from the European Centre for Medium-Range 


\section{Diurnal* and annual cycle heatmaps for selected variables over Europe and the United States}

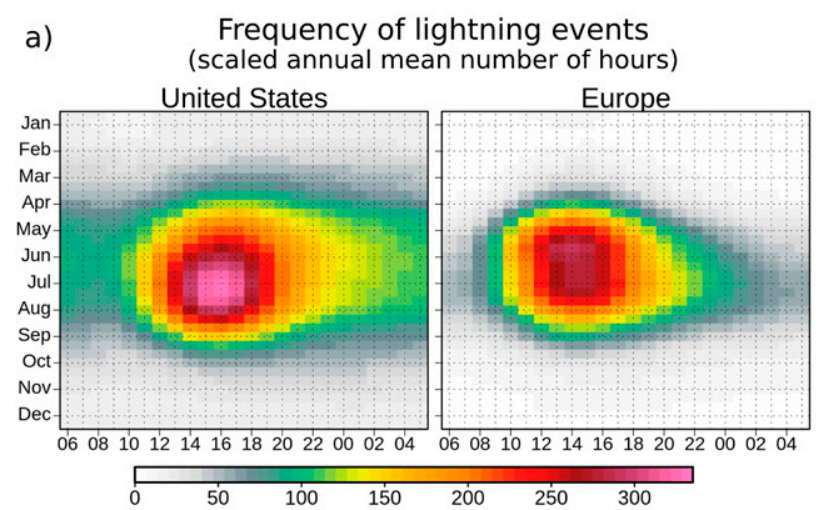

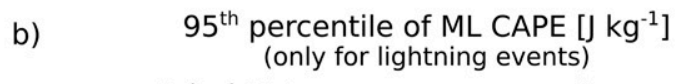

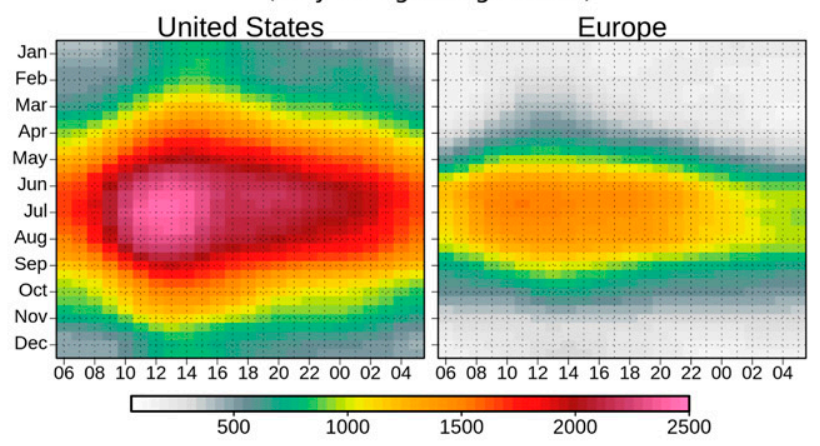

d) $95^{\text {th }}$ percentile of ML WMAXSHEAR $\left[\mathrm{m}^{2} \mathrm{~s}^{-2}\right]$ (only for lightning events)

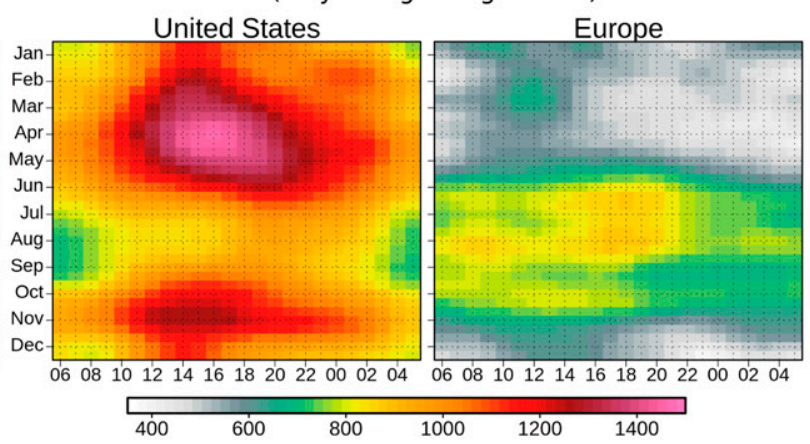

f) $\quad 50^{\text {th }}$ percentile of absolute ML CIN [J kg-1 $]$ (only for lightning events)

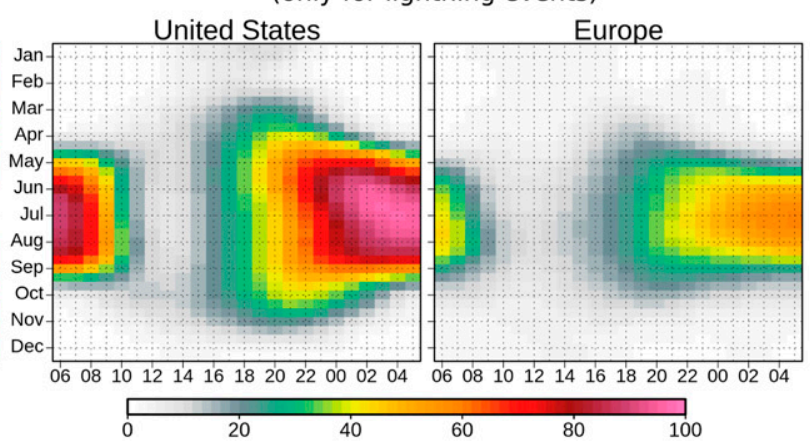

* - values on the horizontal axis denote time in UTC for Europe and CST for the United States

FIG. 15. Diurnal (horizontal axis) and annual (vertical axis) cycle heat maps for the (a) frequency of lightning events (scaled between regions to annual mean number of hours), (b) 95th percentile of ML CAPE, (c) 50th percentile of 0-6-km wind shear, (d) 95th percentile of ML WMAXSHEAR, (e) 50th percentile of 0-1-km wind shear, and (f) 50th percentile of ML CIN. Time is represented in UTC for Europe and CST for the United States. Each month is divided into three 9-11-day periods (depending on the number of days in the month). Axis labels indicate the middle part of each month. Values are derived from a period of 2006-18 for Europe (ATDnet) and 1989-2018 for the United States (NLDN).

Weather Forecasts (ECMWF), Copernicus Climate Change Service (C3S) at Climate Data Store (https://cds.climate. copernicus.eu/). The National Lightning Detection Network dataset was provided by the NOAA National Severe Storms Laboratory and due to the proprietary nature of the data, cannot be made openly available, contact lightning@ou.edu for usage information. ATDnet lightning dataset was provided by
United Kingdom Met Office and due to the proprietary nature of the data, cannot be made openly available, contact debbie. osullivan@metoffice.gov.uk for usage information. United States severe weather reports are available at Storm Prediction Center Storm Data (https://www.spc.noaa.gov/wcm/). European severe weather reports are available at European Severe Weather Database (https://eswd.eu/). 


\section{Diurnal* and annual cycle heatmaps for selected variables over Europe and the United States}

a) $50^{\text {th }}$ percentile of $\mathrm{ML}$ mixing ratio $\left[\mathrm{g} \mathrm{kg}^{-1}\right]$ (only for lightning events)

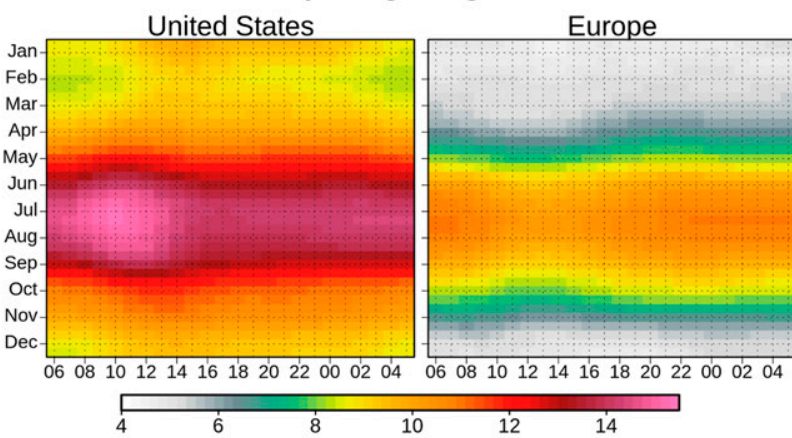

c) $50^{\text {th }}$ percentile of $0-3 \mathrm{~km}$ lapse rate $\left[\mathrm{K} \mathrm{km}^{-1}\right]$ (only for lightning events)

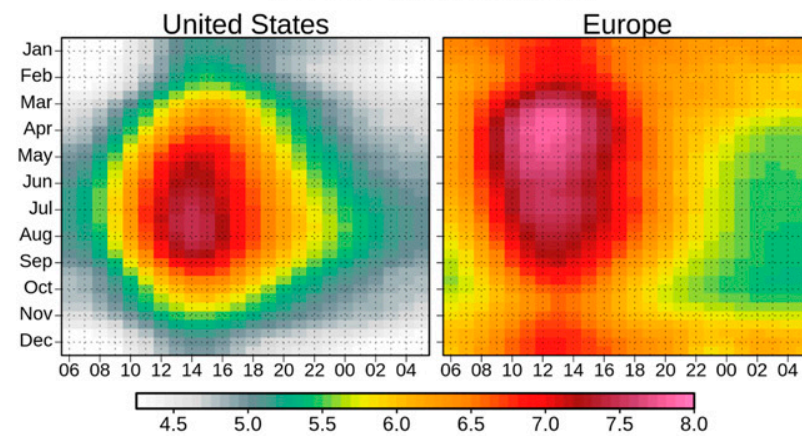

\section{e) $\quad 50^{\text {th }}$ percentile of ML LFC [m AGL] (only for lightning events)}
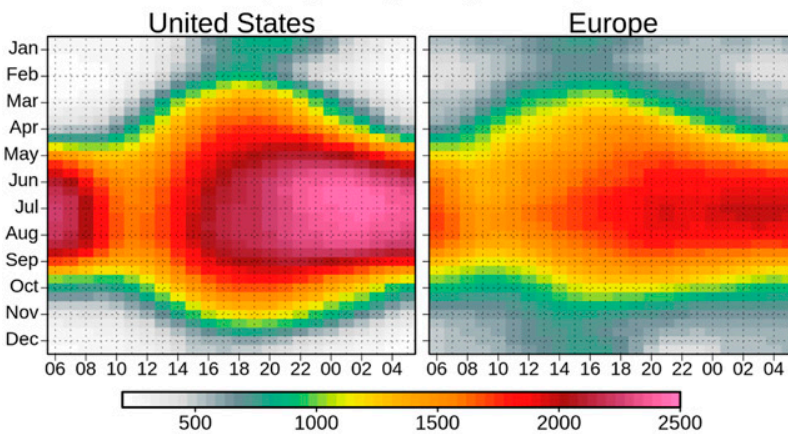

b) $50^{\text {th }}$ percentile of $2-4 \mathrm{~km}$ lapse rate $\left[\mathrm{K} \mathrm{km}^{-1}\right]$ (only for lightning events)

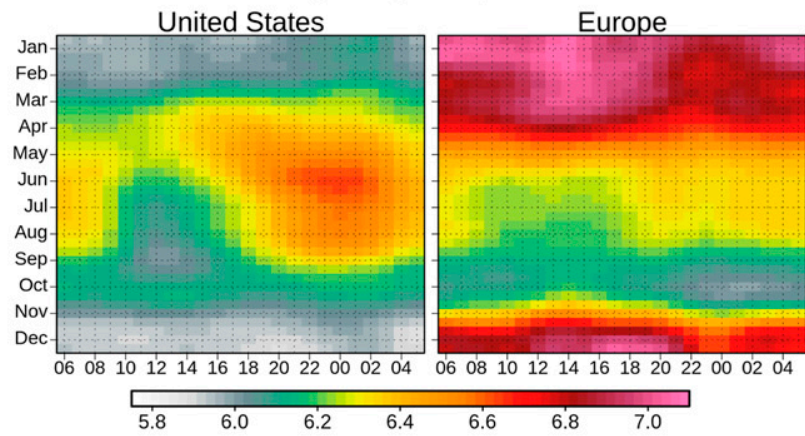

d) $50^{\text {th }}$ percentile of ML LCL [m AGL] (only for lightning events)
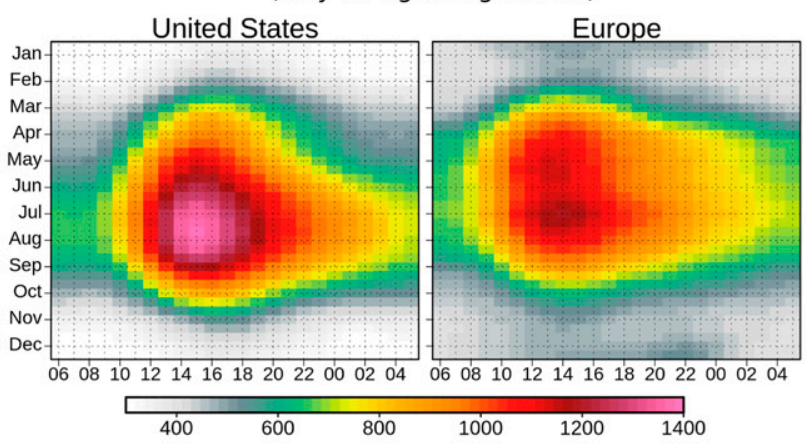

f) $50^{\text {th }}$ percentile of ML EL [m AGL] (only for lightning events)

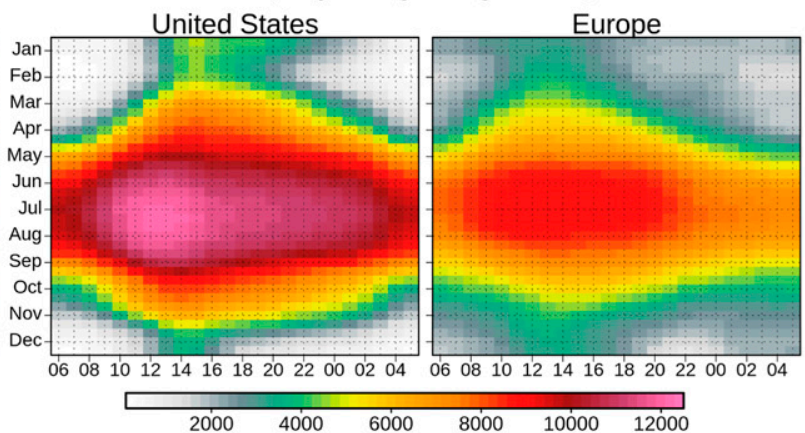

* - values on the horizontal axis denote time in UTC for Europe and CST for the United States

FIG. 16. As in Fig. 15, but for the (a) 50th percentile of ML mixing ratio, (b) 50th percentile of 2-4-km temperature lapse rate, (c) 50th percentile of 0-3-km temperature lapse rate, (d) 50th percentile of ML LCL, (e) 50th percentile of ML LFC, and (f) 50th percentile of ML EL.

\section{APPENDIX A}

\section{Formulas of Composite Parameters Used in the Study}

\section{a. Significant hail parameter}

The Storm Prediction Center (see https://www.spc.noaa.gov) defines the significant hail parameter as

$\mathrm{SHIP}=\left[\mathrm{CAPE} \times \mathrm{MR} \times \mathrm{LR} \times\left(-T_{500 \mathrm{hPa}}\right) \times \mathrm{BS}\right] / 42000000$, where CAPE is the most unstable CAPE $\left(\mathrm{J} \mathrm{kg}^{-1}\right)$, MR is the mixing ratio of most unstable parcel $\left(\mathrm{g} \mathrm{kg}^{-1}\right)$, LR is the 500-700-hPa temperature lapse rate $\left(\mathrm{K} \mathrm{km}^{-1}\right), T_{500 \mathrm{hPa}}$ is the temperature at $500 \mathrm{hPa}\left({ }^{\circ} \mathrm{C}\right)$, and $\mathrm{BS}$ is the $0-6 \mathrm{~km}$ AGL bulk wind shear $\left(\mathrm{m} \mathrm{s}^{-1}\right)$.

In addition, if CAPE $<1300 \mathrm{~J} \mathrm{~kg}^{-1}$, then SHIP $=$ SHIP $\times$ $\left(\right.$ CAPE $\left./ 1300 \mathrm{~J} \mathrm{~kg}^{-1}\right)$; if LR $<5.8 \mathrm{~K} \mathrm{~km}^{-1}$, then SHIP $=$ SHIP $\times$ $\left(\mathrm{LR} / 5.8 \mathrm{~K} \mathrm{~km}^{-1}\right)$; if the freezing level height $(\mathrm{FL})<2400 \mathrm{~m}$, then SHIP $=$ SHIP $\times(\mathrm{FL} / 2400 \mathrm{~m})$; if MR $<11 \mathrm{~g} \mathrm{~kg}^{-1}$, then 
a)

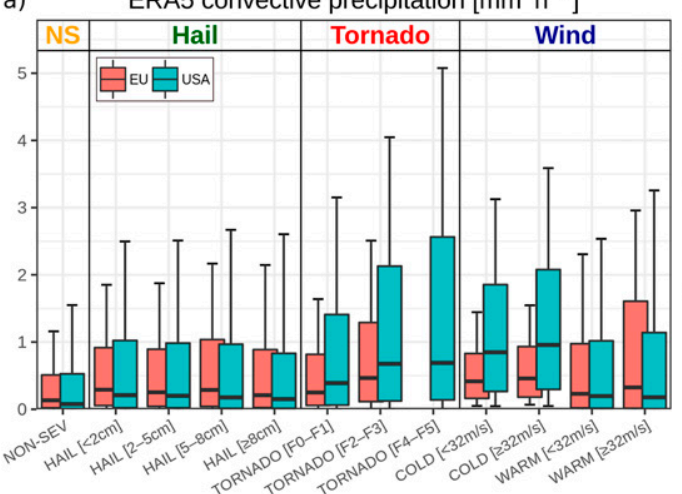

b) Lightning activity [flashes $\mathrm{h}^{-1}$ ]

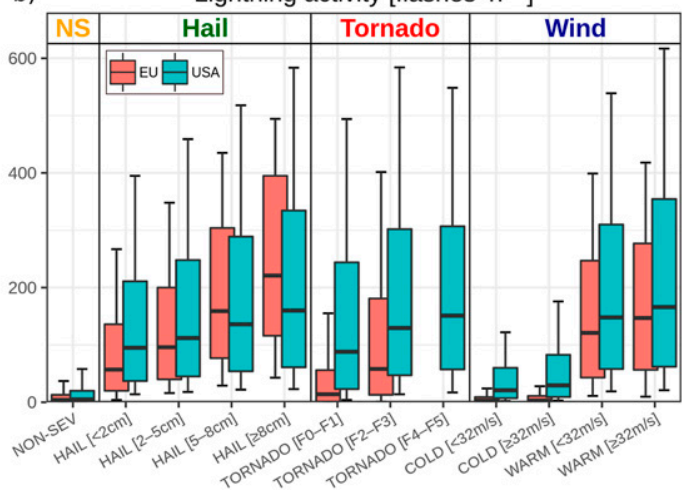

FIG. B1. As in Fig. 2, but for (a) ERA5-modeled 1-h convective precipitation accumulation and (b) NLDN and ATDnet hourly flash count.

$\mathrm{MR}=11 \mathrm{~g} \mathrm{~kg}^{-1}$; if $\mathrm{MR}>13.6 \mathrm{~g} \mathrm{~kg}^{-1}$, then $\mathrm{MR}=13.6 \mathrm{~g} \mathrm{~kg}^{-1}$; if $T_{500 \mathrm{hPa}}>-5^{\circ} \mathrm{C}$, then $T_{500 \mathrm{hPa}}=-5^{\circ} \mathrm{C}$; if $\mathrm{BS}<7 \mathrm{~m} \mathrm{~s}^{-1}$, then $\mathrm{BS}=7 \mathrm{~m} \mathrm{~s}^{-1}$; and if $\mathrm{BS}>27 \mathrm{~m} \mathrm{~s}^{-1}$ then $\mathrm{BS}=27 \mathrm{~m} \mathrm{~s}^{-1}$.

\section{b. Supercell composite parameter}

The supercell composite parameter is defined as (Gropp and Davenport 2018)

$$
\begin{aligned}
\mathrm{SCP}= & \left(\mathrm{CAPE} / 1000 \mathrm{~J} \mathrm{~kg}^{-1}\right) \times\left(\mathrm{BS}_{\mathrm{eff}} / 20 \mathrm{~m} \mathrm{~s}^{-1}\right) \\
& \times\left(\mathrm{SRH}_{\mathrm{eff}} / 50 \mathrm{~m}^{2} \mathrm{~s}^{-2}\right) \times\left(-40 \mathrm{~J} \mathrm{~kg}^{-1} / \mathrm{CIN}\right)
\end{aligned}
$$

where CAPE is the most unstable CAPE $\left(\mathrm{J} \mathrm{kg}^{-1}\right), \mathrm{CIN}$ is the most unstable CIN $\left(\mathrm{J} \mathrm{kg}^{-1}\right), \mathrm{SRH}_{\text {eff }}$ is the effective storm-relative helicity $\left(\mathrm{m}^{2} \mathrm{~s}^{-2}\right)$, and $\mathrm{BS}_{\text {eff }}$ is the effective bulk wind shear $\left(\mathrm{m} \mathrm{s}^{-1}\right)$.

\section{Diurnal* and annual cycle heatmaps for selected variables over Europe and the United States}

a) $99^{\text {th }}$ percentile of Significant Hail Parameter (only for lightning events)

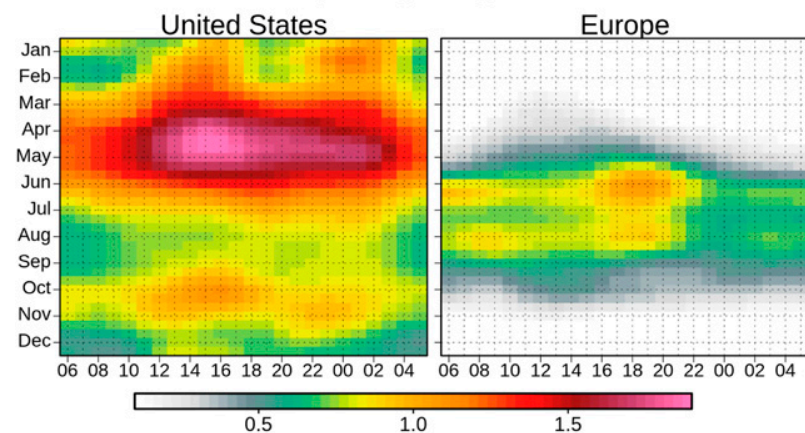

c) $99^{\text {th }}$ percentile of Significant Tornado Parameter (only for lightning events)

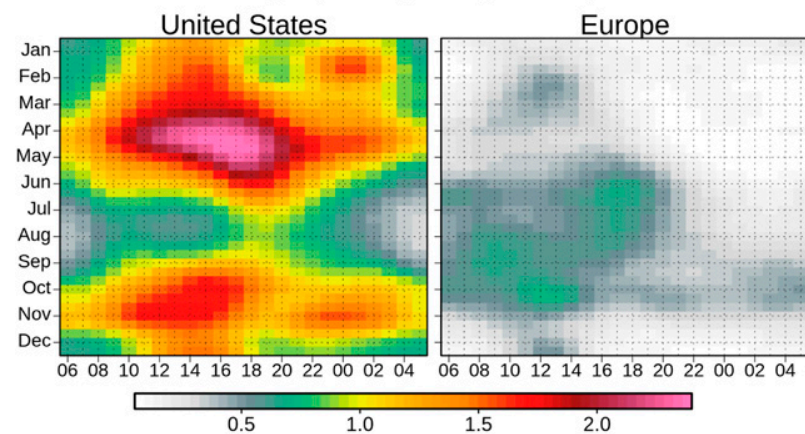

b) $99^{\text {th }}$ percentile of Supercell Composite Parameter (only for lightning events)

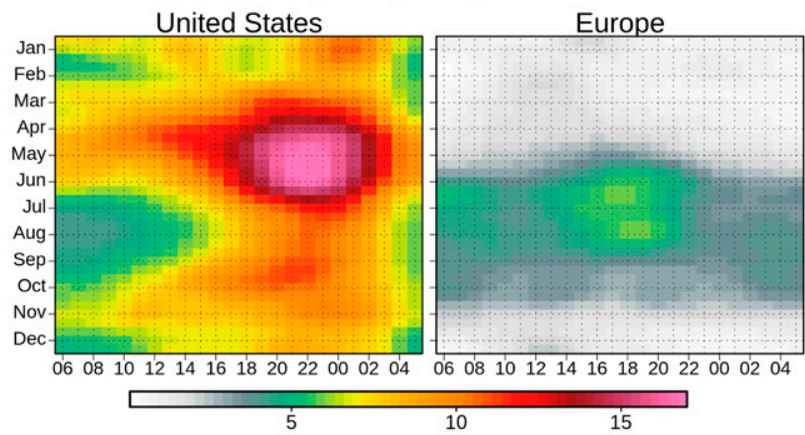

d) $50^{\text {th }}$ percentile of most-unstable parcel height [m AGL] (only for lightning events)

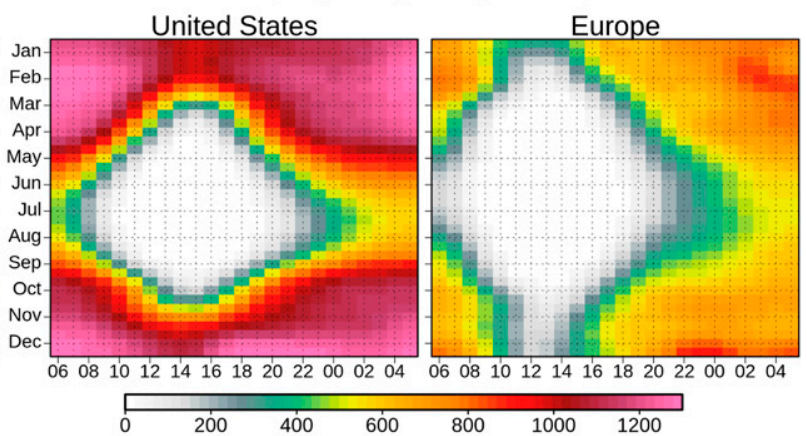

* - values on the horizontal axis denote time in UTC for Europe and CST for the United States

FIG. C1. As in Fig. 15, but for the (a) 99th percentile of the significant hail parameter, (b) 99th percentile of the supercell composite parameter, (c) 99th percentile of the significant tornado parameter, and (d) 50th percentile of the most unstable parcel height. 
In addition, if $\mathrm{BS}_{\mathrm{eff}}>20 \mathrm{~m} \mathrm{~s}^{-1}$, then $\mathrm{BS}_{\mathrm{eff}}=20 \mathrm{~m} \mathrm{~s}^{-1}$; if $\mathrm{BS}_{\text {eff }}<10 \mathrm{~m} \mathrm{~s}^{-1}$, then $\mathrm{BS}_{\text {eff }}=0$; and if CIN $>-40 \mathrm{~J} \mathrm{~kg}^{-1}$, then $\mathrm{CIN}=-40 \mathrm{~J} \mathrm{~kg}^{-1}$.

\section{c. Significant tornado parameter}

The significant tornado parameter is defined as (Coffer et al. 2019)

$$
\begin{aligned}
\mathrm{STP}= & \left(\mathrm{CAPE} / 1500 \mathrm{~J} \mathrm{~kg}^{-1}\right) \times[(2000-\mathrm{LCL}) / 1000 \mathrm{~m}] \\
& \times\left(\mathrm{SRH} / 50 \mathrm{~m}^{2} \mathrm{~s}^{-2}\right) \times\left(\mathrm{BS}_{\mathrm{eff}} / 20 \mathrm{~m} \mathrm{~s}^{-1}\right) \\
& \times\left[(200+\mathrm{CIN}) / 150 \mathrm{~J} \mathrm{~kg}^{-1}\right]
\end{aligned}
$$

where CAPE is the mixed-layer CAPE $\left(\mathrm{J} \mathrm{kg}^{-1}\right), \mathrm{CIN}$ is the mixed-layer CIN $\left(\mathrm{J} \mathrm{kg}^{-1}\right)$, LCL is the mixed-layer LCL ( $\mathrm{m}$ AGL), SRH is the 0-500 $\mathrm{m}$ AGL storm-relative helicity $\left(\mathrm{m}^{2} \mathrm{~s}^{-2}\right)$, and $\mathrm{BS}_{\text {eff }}$ is the effective bulk wind shear $\left(\mathrm{m} \mathrm{s}^{-1}\right)$.

In addition, if $\mathrm{LCL}<1000 \mathrm{~m}$, then $\mathrm{LCL}=1000 \mathrm{~m}$; if $\mathrm{LCL}>$ $2000 \mathrm{~m}$, then $\mathrm{LCL}=2000 \mathrm{~m}$; if $\mathrm{CIN}>-50 \mathrm{~J} \mathrm{~kg}^{-1}$, then CIN $=-50 \mathrm{~J} \mathrm{~kg}^{-1}$; if $\mathrm{CIN}<-200 \mathrm{~J} \mathrm{~kg}^{-1}$, then $\mathrm{CIN}=$ $-200 \mathrm{~J} \mathrm{~kg}^{-1}$; if $\mathrm{BS}_{\text {eff }}>30 \mathrm{~m} \mathrm{~s}^{-1}$, then $\mathrm{BS}_{\text {eff }}=30 \mathrm{~m} \mathrm{~s}^{-1}$; and if $\mathrm{BS}_{\text {eff }}<12.5 \mathrm{~m} \mathrm{~s}^{-1}$, then $\mathrm{BS}_{\text {eff }}=0$.

\section{APPENDIX B}

\section{Additional Box-and-Whisker Plots}

Figure B1 shows box-and-whisker plots of ERA5 convective precipitation accumulation and flash rates as severe thunderstorm proxies using data from the lightning detection networks for the United States and Europe.

\section{APPENDIX C}

\section{Additional Diurnal and Annual Cycle Plots}

Figure C1 shows diurnal and annual cycle heat maps for the significant hail parameter, the supercell composite parameter, the significant tornado parameter, and the most unstable parcel height using data from the lightning detection networks for the United States and Europe.

\section{REFERENCES}

Allen, J. T., and D. J. Karoly, 2014: A climatology of Australian severe thunderstorm environments 1979-2011: Inter-annual variability and ENSO influence. Int. J. Climatol., 34, 81-97, https://doi.org/10.1002/joc.3667.

— , and E. R. Allen, 2016: A review of severe thunderstorms in Australia. Atmos. Res., 178-179, 347-366, https://doi.org/ 10.1016/j.atmosres.2016.03.011.

—_, D. J. Karoly, and G. A. Mills, 2011: A severe thunderstorm climatology for Australia and associated thunderstorm environments. Aust. Meteor. Oceanogr. J., 61, 143-158, https:// doi.org/10.22499/2.6103.001.

— _ _ , and K. J. Walsh, 2014: Future Australian severe thunderstorm environments. Part I: A novel evaluation and climatology of convective parameters from two climate models for the late twentieth century. J. Climate, 27, 3827-3847, https://doi.org/10.1175/JCLI-D-13-00425.1.

—, M. K. Tippett, and A. H. Sobel, 2015: An empirical model relating U.S. monthly hail occurrence to large-scale meteo- rological environment. J. Adv. Model. Earth Syst., 7, 226-243, https://doi.org/10.1002/2014MS000397.

Anderson-Frey, A. K., Y. P. Richardson, A. R. Dean, R. L. Thompson, and B. T. Smith, 2016: Investigation of near-storm environments for tornado events and warnings. Wea. Forecasting, 31, 1771-1790, https://doi.org/10.1175/WAF-D-16-0046.1.

,,,,---- and,- 2018 : Near-storm environments of outbreak and isolated tornadoes. Wea. Forecasting, 33, 13971412, https://doi.org/10.1175/WAF-D-18-0057.1.

$-, \ldots,-, \ldots$, and -2019 : Characteristics of tornado events and warnings in the southeastern United States. Wea. Forecasting, 34, 1017-1034, https://doi.org/10.1175/WAF-D18-0211.1.

Antonescu, B., J. G. Fairman, and D. M. Schultz, 2018: What is the worst that could happen? Reexamining the 24-25 June 1967 tornado outbreak over western Europe. Wea. Climate Soc., 10, 323-340, https://doi.org/10.1175/WCAS-D-17-0076.1.

Atkins, N. T., and R. M. Wakimoto, 1991: Wet microburst activity over the southeastern United States: Implications for forecasting. Wea. Forecasting, 6, 470-482, hitps//doiorg/10.1175/15200434(1991)006 <0470. WMAOTS $>20.002$

Banacos, P. C., and M. L. Ekster, 2010: The association of the elevated mixed layer with significant severe weather events in the northeastern United States. Wea. Forecasting, 25, 10821102, https://doi.org/10.1175/2010WAF2222363.1.

Blamey, R. C., C. Middleton, C. Lennard, and C. J. C. Reason, 2017: A climatology of potential severe convective environments across South Africa. Climate Dyn., 49, 2161-2178, https://doi.org/10.1007/s00382-016-3434-7.

Brooks, H. E., 2009: Proximity soundings for severe convection for Europe and the United States from reanalysis data. Atmos. Res., 93, 546-553, https://doi.org/10.1016/j.atmosres.2008.10.005.

- 2013: Severe thunderstorms and climate change. Atmos. Res., 123, 129-138, https://doi.org/10.1016/j.atmosres.2012.04.002.

_ , and C. A. Doswell, 2001: Some aspects of the international climatology of tornadoes by damage classification. Atmos. Res., 56, 191-201, https://doi.org/10.1016/S0169-8095(00)00098-3.

_ J. W. Lee, and J. P. Craven, 2003: The spatial distribution of severe thunderstorm and tornado environments from global reanalysis data. Atmos. Res., 67-68, 73-94, https://doi.org/ 10.1016/S0169-8095(03)00045-0.

_ - A. R. Anderson, K. Riemann, I. Ebbers, and H. Flachs, 2007: Climatological aspects of convective parameters from the NCAR/NCEP reanalysis. Atmos. Res., 83, 294-305, https:// doi.org/10.1016/j.atmosres.2005.08.005.

- and Coauthors, 2011: Evaluation of European Storm Forecast Experiment (ESTOFEX) forecasts. Atmos. Res., 100, 538-546, https://doi.org/10.1016/j.atmosres.2010.09.004.

Bruick, Z. S., K. L. Rasmussen, and D. J. Cecil, 2019: Subtropical South American hailstorm characteristics and environments. Mon. Wea. Rev., 147, 4289-4304, https://doi.org/10.1175/MWRD-19-0011.1.

Bunkers, M. J., B. A. Klimowski, J. W. Zeitler, R. L. Thompson, and M. L. Weisman, 2000: Predicting supercell motion using a new hodograph technique. Wea. Forecasting, 15, 61-79, https://doi.org/ 10.1175/1520-0434(2000)015<0061:PSMUAN>2.0.CO;2.

Carlson, T. N., and F. H. Ludlam, 1968: Conditions for the occurrence of severe local storms. Tellus, 20, 203-226, https:// doi.org/10.3402/tellusa.v20i2.10002.

Celiński-Mysław, D., A. Palarz, and M. Taszarek, 2020: Climatology and atmospheric conditions associated with cool season bow echo storms in Poland. Atmos. Res., 240, 104944, https://doi.org/ 10.1016/j.atmosres.2020.104944. 
Chen, J., A. Dai, Y. Zhang, and K. L. Rasmussen, 2020: Changes in convective available potential energy and convective inhibition under global warming. J. Climate, 33, 2025-2050, https:// doi.org/10.1175/JCLI-D-19-0461.1.

Chernokulsky, A. V., M. V. Kurgansky, and I. I. Mokhov, 2019: On characteristic reanalysis-based values of convective instability indices for northern Eurasia tornadoes. IOP Conf. Ser. Earth Environ. Sci., 231, 012012, https://doi.org/10.1088/1755-1315/231/1/012012.

— , and Coauthors, 2020: Tornadoes in northern Eurasia: From the middle age to the information era. Mon. Wea. Rev., 148, 3081-3110, https://doi.org/10.1175/MWR-D-19-0251.1.

Coffer, B. E., and M. D. Parker, 2018: Is there a "tipping point" between simulated nontornadic and tornadic supercells in VORTEX2 environments? Mon. Wea. Rev., 146, 2667-2693, https://doi.org/10.1175/MWR-D-18-0050.1.

,$- \longrightarrow$, R. L. Thompson, B. T. Smith, and R. E. Jewell, 2019: Using near-ground storm relative helicity in supercell tornado forecasting. Wea. Forecasting, 34, 1417-1435, https://doi.org/ 10.1175/WAF-D-19-0115.1.

Coniglio, M. C., H. E. Brooks, S. J. Weiss, and S. F. Corfidi, 2007: Forecasting the maintenance of quasi-linear mesoscale convective systems. Wea. Forecasting, 22, 556-570, https://doi.org/ 10.1175/WAF1006.1.

Copernicus Climate Change Service, 2017: ERA5: Fifth generation of ECMWF atmospheric reanalyses of the global climate. Copernicus Climate Change Service Climate Data Store (CDS), accessed 10 February 2020, https://cds.climate.copernicus.eu/ cdsapp\#!/home.

Corfidi, S. F., S. J. Corfidi, D. A. Imy, and A. L. Logan, 2006: A preliminary study of severe wind-producing MCSs in environments of limited moisture. Wea. Forecasting, 21, 715-734, https://doi.org/10.1175/WAF947.1.

—, M. C. Coniglio, A. E. Cohen, and C. M. Mead, 2016: A proposed revision to the definition of "derecho." Bull. Amer. Meteor. Soc., 97, 935-949, https://doi.org/10.1175/BAMS-D-14-00254.1.

Craven, J. P., and H. E. Brooks, 2004: Baseline climatology of sounding derived parameters associated with deep moist convection. Natl. Wea. Dig., 28, 13-24, http://www.nssl.noaa.gov/ users/brooks/public_html/papers/cravenbrooksnwa.pdf.

Cummins, K. L., and M. J. Murphy, 2009: An overview of lightning locating systems: History, techniques, and data uses, with an indepth look at the U.S. NLDN. IEEE Trans. Electromagn. Compat., 51, 499-518, https://doi.org/10.1109/TEMC.2009.2023450.

Davies, J. M., 1993: Small tornadic supercells in the central plains. Preprints, 17th Conf. on Severe Local Storms, St. Louis, MO, Amer. Meteor. Soc., 305-309.

— 2006: Tornadoes in environments with small helicity and/or high LCL heights. Wea. Forecasting, 21, 579-594, https:// doi.org/10.1175/WAF928.1.

Doswell, C. A., and E. N. Rasmussen, 1994: The effect of neglecting the virtual temperature correction on CAPE calculations. Wea. Climate Extremes, 9, 625-629, https://doi.org/10.1175/ 1520-0434(1994)009<0625:TEONTV>2.0.CO;2.

— , H. E. Brooks, and R. A. Maddox, 1996: Flash flood forecasting: An ingredients-based methodology. Wea. Forecasting, 11, 560-581, https://doi.org/10.1175/1520-0434(1996)011<0560: FFFAIB $>2.0 . \mathrm{CO} ; 2$.

Dotzek, N., P. Groenemeijer, B. Feuerstein, and A. M. Holzer, 2009: Overview of ESSL's severe convective storms research using the European Severe Weather Database ESWD. Atmos. Res., 93, 575-586, https://doi.org/10.1016/j.atmosres.2008.10.020.

Edwards, R., J. T. Allen, and G. W. Carbin, 2018: Reliability and climatological impacts of convective wind estimations. J. Appl.
Meteor. Climatol., 57, 1825-1845, https://doi.org/10.1175/ JAMC-D-17-0306.1.

Enno, S. E., J. Sugier, R. Alber, and M. Seltzer, 2020: Lightning flash density in Europe based on 10 years of ATDnet data. Atmos. Res., 235, 104769, https://doi.org/10.1016/j.atmosres.2019.104769.

Evans, J. S., and C. A. Doswell, 2001: Examination of derecho environments using proximity soundings. Wea. Forecasting, 16, 329-342, https://doi.org/10.1175/1520-0434(2001)016<0329:EODEUP> 2.0.CO;2.

Fujita, T. T., 1971: Proposed characterization of tornadoes and hurricanes by area and intensity. SMRP research paper, University of Chicago, Vol. 91, 42 pp.

Gatzen, C., 2011: A 10-year climatology of cold-season narrow cold-frontal rainbands in Germany. Atmos. Res., 100, 366-370, https://doi.org/10.1016/j.atmosres.2010.09.018.

, A. H. Fink, D. M. Schultz, and J. G. Pinto, 2020: An 18-year climatology of derechos in Germany. Nat. Hazards Earth Syst. Sci., 20, 1335-1351, https://doi.org/10.5194/nhess-20-1335-2020.

Gensini, V. A., and W. S. Ashley, 2011: Climatology of potentially severe convective environments from the North American regional reanalysis. Electron. J. Severe Storms Meteor., 6 (8), https://ejssm.org/ojs/index.php/ejssm/article/viewArticle/85.

— nado frequency. npj Climate Atmos. Sci., 1, 38, https://doi.org/ 10.1038/S41612-018-0048-2.

- and L. Bravo de Guenni, 2019: Environmental covariate representation of seasonal U.S. tornado frequency. J. Appl. Meteor. Climatol., 58, 1353-1367, https://doi.org/10.1175/JAMC-D-18-0305.1.

- T. T. L. Mote, and H. E. Brooks, 2014: Severe-thunderstorm reanalysis environments and collocated radiosonde observations. J. Appl. Meteor. Climatol., 53, 742-751, https://doi.org/ 10.1175/JAMC-D-13-0263.1.

Grams, J. S., R. L. Thompson, D. V. Snively, J. A. Prentice, G. M. Hodges, and L. J. Reames, 2012: A climatology and comparison of parameters for significant tornado events in the United States. Wea. Forecasting, 27, 106-123, https://doi.org/10.1175/ WAF-D-11-00008.1.

Griffiths, D. J., J. R. Colquhoun, K. L. Batt, and T. R. Casinader, 1993: Severe thunderstorms in New South Wales: Climatology and means of assessing the impact of climate change. Climatic Change, 25, 369-388, https://doi.org/10.1007/BF01098382.

Groenemeijer, P. H., and A. van Delden, 2007: Sounding-derived parameters associated with large hail and tornadoes in the Netherlands. Atmos. Res., 83, 473-487, https://doi.org/10.1016/ j.atmosres.2005.08.006.

- , and T. Kühne, 2014: A climatology of tornadoes in Europe: Results from the European Severe Weather Database. Mon. Wea. Rev., 142, 4775-4790, https://doi.org/10.1175/MWR-D14-00107.1.

- and Coauthors, 2017: Severe convective storms in Europe: Ten years of research and education at the European Severe Storms Laboratory. Bull. Amer. Meteor. Soc., 98, 2641-2651, https://doi.org/10.1175/BAMS-D-16-0067.1.

Gropp, M. E., and C. E. Davenport, 2018: The impact of the nocturnal transition on the lifetime and evolution of supercell thunderstorms in the Great Plains. Wea. Forecasting, 33, 10451061, https://doi.org/10.1175/WAF-D-17-0150.1.

Hamid, K., 2012: Investigation of the passage of a derecho in Belgium. Atmos. Res., 107, 86-105, https://doi.org/10.1016/ j.atmosres.2011.12.013.

Hart, J. A., and A. E. Cohen, 2016: The challenge of forecasting significant tornadoes from June to October using convective 
parameters. Wea. Forecasting, 31, 2075-2084, https://doi.org/ 10.1175/WAF-D-16-0005.1.

Hersbach, H., and Coauthors, 2020: The ERA5 global reanalysis. Quart. J. Roy. Meteor. Soc., 146, 1999-2049, https://doi.org/ 10.1002/qj.3803.

Hitchens, N. M., and H. E. Brooks, 2014: Evaluation of the Storm Prediction Center's convective outlooks from day 3 through day 1. Wea. Forecasting, 29, 1134-1142, https://doi.org/10.1175/ WAF-D-13-00132.1.

Ingrosso, R., P. Lionello, M. M. Miglietta, and G. Salvadori, 2020: A statistical investigation of mesoscale precursors of significant tornadoes: The Italian case study. Atmosphere, 11, 301, https://doi.org/10.3390/atmos11030301.

Johns, R. H., and C. A. Doswell, 1992: Severe local storms forecasting. Wea. Forecasting, 7, 588-612, https://doi.org/10.1175/ 1520-0434(1992)007<0588:SLSF>2.0.CO;2.

Johnson, A. W., and K. E. Sugden, 2014: Evaluation of soundingderived thermodynamic and wind-related parameters associated with large hail events. Electron. J. Severe Storms Meteor., 9 (5), https://www.ejssm.org/ojs/index.php/ejssm/article/viewArticle/137.

Kaltenböck, R., G. Diendorfer, and N. Dotzek, 2009: Evaluation of thunderstorm indices from ECMWF analyses, lightning data and severe storm reports. Atmos. Res., 93, 381-396, https:// doi.org/10.1016/j.atmosres.2008.11.005.

King, A. T., and A. D. Kennedy, 2019: North American supercell environments in atmospheric reanalyses and RUC-2. J. Appl. Meteor. Climatol., 58, 71-92, https://doi.org/10.1175/JAMC-D-18-0015.1.

Kingfield, D. M., K. M. Calhoun, and K. M. de Beurs, 2017: Antenna structures and cloud-to-ground lightning location: 1995-2015. Geophys. Res. Lett., 44, 5203-5212, https://doi.org/ 10.1002/2017GL073449.

Koehler, T. L., 2020: Cloud-to-ground lightning flash density and thunderstorm day distributions over the contiguous United States derived from NLDN measurements: 1993-2018. Mon. Wea. Rev., 148, 313-332, https://doi.org/10.1175/MWR-D-19-0211.1.

Kolendowicz, L., 2012: Synoptic patterns associated with thunderstorms in Poland. Meteor. Z., 21, 145-156, https://doi.org/ 10.1127/0941-2948/2012/0272.

Kuchera, E. L., and M. D. Parker, 2006: Severe convective wind environments. Wea. Forecasting, 21, 595-612, https://doi.org/ 10.1175/WAF931.1.

Kumjian, M. R., and K. Lombardo, 2020: A hail growth trajectory model for exploring the environmental controls on hail size: Model physics and idealized tests. J. Atmos. Sci., 77, 27652791, https://doi.org/10.1175/JAS-D-20-0016.1.

Kunz, M., U. Blahak, J. Handwerker, M. Schmidberger, H. J. Punge, S. Mohr, E. Fluck, and K. M. Bedka, 2018: The severe hailstorm in southwest Germany on 28 July 2013: Characteristics, impacts and meteorological conditions. Quart. J. Roy. Meteor. Soc., 144, 231-250, https://doi.org/10.1002/qj.3197.

, J. Wandel, E. Fluck, S. Baumstark, S. Mohr, and S. Schemm, 2020: Ambient conditions prevailing during hail events in central Europe. Nat. Hazards Earth Syst. Sci., 20, 1867-1887, https://doi.org/10.5194/nhess-20-1867-2020.

Li, F., D. R. Chavas, K. A. Reed, and D. T. Dawson, 2020: Climatology of severe local storm environments and synopticscale features over North America in ERA5 reanalysis and CAM6 simulation. J. Climate, 33, 8339-8365, https://doi.org/ 10.1175/JCLI-D-19-0986.1.

Li, M., D.-L. Zhang, J. Sun, and Q. Zhang, 2018: A statistical analysis of hail events and their environmental conditions in China during 2008-15. J. Appl. Meteor. Climatol., 57, 28172833, https://doi.org/10.1175/JAMC-D-18-0109.1.
Markowski, P. M., J. M. Straka, E. N. Rasmussen, and D. O. Blanchard, 1998: Variability of storm-relative helicity during VORTEX. Mon. Wea. Rev., 126, 2959-2971, https:// doi.org/10.1175/1520-0493(1998)126<2959:VOSRHD>2.0. $\mathrm{CO} ; 2$.

—_ — - and ——, 2002: Direct surface thermodynamic observations within the rear-flank downdrafts of nontornadic and tornadic supercells. Mon. Wea. Rev., 130, 1692-1721, https://doi.org/10.1175/1520-0493(2002)130<1692:DSTOWT> 2.0.CO;2.

Marsh, P. T., H. E. Brooks, and D. J. Karoly, 2009: Preliminary investigation into the severe thunderstorm environment of Europe simulated by the Community Climate System Model 3. Atmos. Res., 93, 607-618, https://doi.org/10.1016/j.atmosres. 2008.09.014.

Mathias, L., V. Ermert, F. D. Kelemen, P. Ludwig, and J. G. Pinto, 2017: Synoptic analysis and hindcast of an intense bow echo in western Europe: The 9 June 2014 storm. Wea. Forecasting, 32, 1121-1141, https://doi.org/10.1175/WAF-D-16-0192.1.

_ P. Ludwig, and J. G. Pinto, 2019: Synoptic-scale conditions and convection-resolving hindcast experiments of a coldseason derecho on 3 January 2014 in western Europe. Nat. Hazards Earth Syst. Sci., 19, 1023-1040, https://doi.org/10.5194/ nhess-19-1023-2019.

Miglietta, M. M., and I. T. Matsangouras, 2018: An updated "climatology" of tornadoes and waterspouts in Italy. Int. J. Climatol., 38, 3667-3683, https://doi.org/10.1002/joc.5526.

Mohr, S., and M. Kunz, 2013: Recent trends and variabilities of convective parameters relevant for hail events in Germany and Europe. Atmos. Res., 123, 211-228, https://doi.org/ 10.1016/j.atmosres.2012.05.016.

Molina, D. S., S. Fernández-González, J. C. S. González, and A. Oliver, 2020: Analysis of sounding derived parameters and application to severe weather events in the Canary Islands. Atmos. Res., 237, 104865, https://doi.org/10.1016/j.atmosres. 2020.104865.

Nag, A., M. J. Murphy, K. L. Cummins, A. E. Pifer, and J. A. Cramer, 2014: Recent evolution of the U.S. National Lightning Detection Network. 23rd Int. Lightning Detection Conf., Tucson, AZ, Vaisala, 6 pp., https://doi.org/10.13140/ 2.1.4443.1047.

Piper, D. A., M. Kunz, J. T. Allen, and S. Mohr, 2019: Investigation of the temporal variability of thunderstorms in central and western Europe and the relation to large-scale flow and teleconnection patterns. Quart. J. Roy. Meteor. Soc., 145, 36443666, https://doi.org/10.1002/qj.3647.

Potvin, C. K., K. L. Elmore, and S. J. Weiss, 2010: Assessing the impacts of proximity sounding criteria on the climatology of significant tornado environments. Wea. Forecasting, 25, 921930, https://doi.org/10.1175/2010WAF2222368.1.

Prein, A. F., and G. J. Holland, 2018: Global estimates of damaging hail hazard. Wea. Climate Extremes, 22, 10-23, https://doi.org/ 10.1016/j.wace.2018.10.004.

Púčik, T., P. Groenemeijer, D. Rýva, and M. Kolář, 2015: Proximity soundings of severe and nonsevere thunderstorms in central Europe. Mon. Wea. Rev., 143, 4805-4821, https:// doi.org/10.1175/MWR-D-15-0104.1.

— , and Coauthors, 2017: Future changes in European severe convection environments in a regional climate model ensemble. J. Climate, 30, 6771-6794, https://doi.org/10.1175/JCLI-D16-0777.1.

Rädler, A. T., P. Groenemeijer, E. Faust, and R. Sausen, 2018: Detecting severe weather trends using an Additive Regressive 
Convective Hazard Model (AR-CHaMo). J. Appl. Meteor. Climatol., 57, 569-587, https://doi.org/10.1175/JAMC-D-17-0132.1.

Rasmussen, E. N., and D. O. Blanchard, 1998: A baseline climatology of sounding-derived supercell and tornado forecast parameters. Wea. Forecasting, 13, 1148-1164, https://doi.org/ 10.1175/1520-0434(1998)013<1148:ABCOSD>2.0.CO;2.

Riemann-Campe, K., K. Fraedrich, and F. Lunkeit, 2009: Global climatology of convective available potential energy (CAPE) and convective inhibition (CIN) in ERA-40 reanalysis. Atmos. Res., 93, 534-545, https://doi.org/10.1016/j.atmosres.2008.09.037.

Rodríguez, O., and J. Bech, 2018: Sounding-derived parameters associated with tornadic storms in Catalonia. Int. J. Climatol., 38, 2400-2414, https://doi.org/10.1002/joc.5343.

—, and —, 2020: Tornadic environments in the Iberian Peninsula and the Balearic Islands based on ERA5 reanalysis. Int. J. Climatol., https://doi.org/10.1002/joc.6825, in press.

Schaefer, J. T., and R. Edwards, 1999: The SPC tornado/severe thunderstorm database. Preprints, 11th Conf. on Applied Climatology, Dallas, TX, Amer. Meteor. Soc., 6.11, https:// ams.confex.com/ams/older/99annual/abstracts/1360.htm.

Shapiro, A., E. Fedorovich, and S. Rahimi, 2016: A unified theory for the Great Plains nocturnal low-level jet. J. Atmos. Sci., 73, 3037-3057, https://doi.org/10.1175/JASD-15-0307.1.

Sherburn, K. D., and M. D. Parker, 2014: Climatology and ingredients of significant severe convection in high-shear, lowCAPE environments. Wea. Forecasting, 29, 854-877, https:// doi.org/10.1175/WAF-D-13-00041.1.

— _ _ _ J. R. King, and G. M. Lackmann, 2016: Composite environments of severe and nonsevere high-shear, low-CAPE convective events. Wea. Forecasting, 31, 1899-1927, https:// doi.org/10.1175/WAF-D-16-0086.1.

Smith, B. T., R. L. Thompson, J. S. Grams, C. Broyles, and H. E. Brooks, 2012: Convective modes for significant severe thunderstorms in the contiguous United States. Part I: Storm classification and climatology. Wea. Forecasting, 27, 11141135, https://doi.org/10.1175/WAF-D-11-00115.1.

Tang, B. H., V. A. Gensini, and C. R. Homeyer, 2019: Trends in United States large hail environments and observations. $n p j$ Climate Atmos. Sci., 2, 45, https://doi.org/10.1038/S41612-0190103-7.

Taszarek, M., H. E. Brooks, and B. Czernecki, 2017: Soundingderived parameters associated with convective hazards in Europe. Mon. Wea. Rev., 145, 1511-1528, https://doi.org/ 10.1175/MWR-D-16-0384.1.

- ——, - — P. Szuster, and K. Fortuniak, 2018: Climatological aspects of convective parameters over Europe: A comparison of ERA-Interim and sounding data. J. Climate, 31, 4281-4308, https://doi.org/10.1175/JCLI-D-17-0596.1.
, and Coauthors, 2019: A climatology of thunderstorms across Europe from a synthesis of multiple data sources. J. Climate, 32, 1813-1837, https://doi.org/10.1175/JCLI-D-18-0372.1.

— , P. Groenemeijer, J. T. Allen, R. Edwards, H. E. Brooks, V. Chmielewski, and S. E. Enno, 2020a: Severe convective storms across Europe and the United States. Part I: Climatology of lightning, large hail, severe wind, and tornadoes. J. Climate, $\mathbf{3 3}$, 10239-10261, https://doi.org/10.1175/JCLI-D-20-0345.1.

— J. T. Allen, H. E. Brooks, N. Pilguj, and B. Czernecki, 2020b: Differing trends in U.S. and European severe thunderstorm environments in a warming climate. Bull. Amer. Meteor. Soc., https://doi.org/10.1175/BAMS-D-20-0004.1, in press.

Thompson, R. L., R. Edwards, J. A. Hart, K. L. Elmore, and P. Markowski, 2003: Close proximity soundings within supercell environments obtained from the Rapid Update Cycle. Wea. Forecasting, 18, 1243-1261, https://doi.org/10.1175/15200434(2003)018<1243: CPSWSE > 2.0.CO;2.

— C. M. Mead, and R. Edwards, 2007: Effective storm-relative helicity and bulk shear in supercell thunderstorm environments. Wea. Forecasting, 22, 102-115, https://doi.org/10.1175/ WAF969.1.

— B. B. Smith, J. S. Grams, A. R. Dean, and C. Broyles, 2012: Convective modes for significant severe thunderstorms in the contiguous United States. Part II: Supercell and QLCS tornado environments. Wea. Forecasting, 27, 1136-1154, https:// doi.org/10.1175/WAF-D-11-00116.1.

, - — , A. Dean, and P. Marsh, 2013: Spatial distributions of tornadic near-storm environments by convective mode. Electron. J. Severe Storms Meteor., 8 (5), http://www.ejssm.org/ojs/index.php/ ejssm/article/viewArticle/125.

Tippett, M. K., A. H. Sobel, and S. J. Camargo, 2012: Association of U.S. tornado occurrence with monthly environmental parameters. Geophys. Res. Lett., 39, L02801, https://doi.org/ 10.1029/2011GL050368.

,,,--- and J. T. Allen, 2014: An empirical relation between U.S. tornado activity and monthly environmental parameters. J. Climate, 27, 2983-2999, https://doi.org/10.1175/ JCLI-D-13-00345.1.

_ J. T. Allen, V. A. Gensini, and H. E. Brooks, 2015: Climate and hazardous convective weather. Curr. Climate Change Rep., 1, 60-73, https://doi.org/10.1007/s40641-015-0006-6.

Trapp, R. J., N. S. Diffenbaugh, H. E. Brooks, M. E. Baldwin, E. D. Robinson, and J. S. Pal, 2007: Changes in severe thunderstorm environment frequency during the 21 st century caused by anthropogenically enhanced global radiative forcing. Proc. Natl. Acad. Sci. USA, 104, 19719-19723, https://doi.org/ 10.1073/pnas.0705494104.

Wapler, K., and P. James, 2015: Thunderstorm occurrence and characteristics in central Europe under different synoptic conditions. Atmos. Res., 158-159, 231-244, https://doi.org/ 10.1016/j.atmosres.2014.07.011. 